\title{
Large-scale experimental investigation of the installation of suction caissons in silt sand
}

Fei Chen*, Jijian Lian, Haijun Wang, Fang Liu, Hongzhen Wang and Yue Zhao

*Corresponding author at: (1) State Key Laboratory of Hydraulic Engineering Simulation and Safety,

Tianjin University, No. 92, Weijin Road, Tianjin 300072, China.

(2) Water Resources and Hydropower Planning and Design General Institute,

No. 2-1, Liupukang Beixiaojie Road, Beijing 100120, China.

Tle.: +8618515021296; fax:+8601063206206.

E-mail address: feichen@tju.edu.cn 


\begin{abstract}
:
Offshore wind power is a rapidly growing area of electricity in China. In the present paper, interaction mechanisms between the caisson for wind turbines and saturated silt sand are investigated with laboratory tests based on two different installation methods, jacking installation and suction installation. For the jacking installation process, the results indicate that the soil pressures inner and outer the skirt of the caisson vary with a similar feature and the magnitudes of the two are nearly balanced. The tip resistance plays a key role in the total jacking installation resistance. This paper examines the predictive performance of $q_{c}$ method and API approach for jacking installation resistance. It is demonstrated that the $q_{c}$ method provides better predictions. The resistance coefficients are recommended. For the case of suction installation, however, the changes of soil pressures inner and outer the skirt are contrasting. Specifically, the inner pressure and tip resistance fall dramatically, but the outer pressure increases when suction is applied. Seepage effect is found to be an important mechanism for the installation of suction caisson. The reduction ratios of the inner friction and tip resistance follow a power-function with the normalized suction. Based on the test results, a prediction method for the required suction has been developed and evaluated.
\end{abstract}

Key words: soil pressure, tip resistance, installation resistance, seepage effect, required suction, resistance reduction 


\section{Introduction}

As a clean and renewable power, wind power is regarded as a promising choice to decrease the use of diesel fuel as well as to solve global energy shortages. In China, wind power has been developed with an accelerating rate in the past ten years. The installed wind-capacity of China had achieved 75300 MW by the end of 2012, which accounted for about $27 \%$ of the total wind-capacity in the world. Most of the generated power in China is from the inland areas except 390 MW from the offshore area, where has been recognized as an important area to develop wind power. At present, there are two offshore wind farms in operation in China and more offshore wind farms are in plan. One is Shanghai Donghai Bridge Offshore Wind Farm and the other is Jiangsu Rudong Offshore Wind Farm. The foundations adopted in the former farm are pile groups with concrete caps [1]. Each foundation consists of eight steel pipe elevated piles, with $85 \mathrm{~m}$ in length, $1.7 \mathrm{~m}$ in diameter and about $0.03 \mathrm{~m}$ in thickness. In the latter wind farm, mono-piles are chosen, with about $50 \mathrm{~m}$ in length and $5 \mathrm{~m}$ in diameter. For the foundation of the wind turbines, two types of foundation are most widely used in the two farms. One is mono-piles and the other is jackets. However, one major disadvantage of them is high expense, which restrains their commercial scale in offshore wind power industry in China.

To decrease the installation cost of the foundation for wind turbines, a type of foundations for offshore platforms, called suction caissons, has recently been developed and used because of its advantages of economic feasibility and environment-friendly work principles [2-6]. Since the first suction caisson was installed for a 3MW wind turbine in 2002 Denmark, more and more efforts have been made on suction caissons for wind turbines [7-10]. For example, a large composite bucket foundation CBF-3-150 (with a 30m diameter and 7m skirt length) developed by Tianjin University for 3.0 MW wind turbine was installed in 2010 Jiangsu, China. Nevertheless, one challenge for suction caissons is how to penetrate into the seabed deep enough to keep the required bearing capacity and stability, especially in sand, where the penetration resistance is quite large [11-12]. To solve this problem, a suction technology is usually employed within the skirt compartment to produce an increased driving force in addition to the self-weight of the caisson. Additionally, the suction will also generate hydraulic gradients in sand, which may reduce the installation resistance. However, attention must be paid when the suction is used, because a high hydraulic gradient will cause piping in the sand within the compartment, which may lead to installation failure [13-14].

To investigate the installation of suction caissons, a number of studies have been completed [15-18]. Most of the 
previous studies stressed the algorithms to calculate the penetration resistance and required suction. Nevertheless, available experiences on the installation are still very limited due mainly to the lack of enough special field and laboratory observations. Furthermore, the soil-skirt interaction and seepage effect during installation have not been investigated thoroughly yet. Consequently, in spite of their promising prospect of engineering application, the suction caissons for wind turbines developed rather slowly so far [1]. As the soils in the sites for many present and potential offshore wind farms in China are silt sand, the research on the installation of suction caissons in this soil is reasonable.

The main objectives of the present study are to investigate (1) the interaction between the sand and skirt during both jacking installation and suction installation conditions; (2) the mechanism of resistance reduction due to seepage; (3) the seepage effect and calculation methods for the required suction. The arrangement of this paper is as follows. In section 2, the materials, the equipment and the approach used for the experiment are presented. The test and predicted results of the jacking installation tests are presented in section 3. The results of the suction installation tests, comparisons with the previous studies and discussions are in section 4. The conclusions of the paper are given in section 5 .

\section{Materials, equipment, and procedures}

\subsection{Materials and equipment}

The silt sand used in the experiment is similar to that of a proposed wind farm site off the east coast of Tianjin City. A grading curve of the sand is shown in Fig. 1. It can be seen that the sand is mainly composed of $76 \%$ fine sand with the grain size in a range of $0.075-0.25 \mathrm{~mm}$, and $20 \%$ silt with the grain size in a range of $0.005-0.075 \mathrm{~mm}$. The sand was evenly rained into the testing platform $(4 \mathrm{~m} \times 4 \mathrm{~m} \times 2.5 \mathrm{~m})$, and each layer was prepared elaborately with a thickness of $0.1 \mathrm{~m}$. After filling, the sand was saturated by elevating the water with a water supply and drainage system with a velocity of $0.5 \mathrm{~m} /$ day. The velocity is slow, to avoid uneven seepage or piping in the sand. And then the sand bed was fully vibrated with a vibrating rod to release the gas in it and left for static settlement for two months. The final form of the sand bed is about $2.0 \mathrm{~m}$ in depth overlaid by $0.15 \mathrm{~m}$ fresh water to keep the sand saturated during the tests. Four cone penetration tests (CPT) were randomly conducted in the sand bed and the cone resistance $q_{c}$ records are shown in Fig. 2. The diameter of the cone used is $35.7 \mathrm{~mm}$ and the penetrating rate is $0.2 \mathrm{~cm} / \mathrm{s}$. Some other soil parameters of the sand bed, such as the saturated density, effective internal friction angle, saturated moisture content, void ratio and relative 
density were tested as well in the soil mechanics laboratory, and the values are $1900 \mathrm{~kg} / \mathrm{m}^{3}, 30^{\circ}, 0.26,0.65$ and 0.63 , respectively.

The used caisson has an internal diameter $(D)$ of $1.5 \mathrm{~m}$ and a skirt height $(L)$ of $0.5 \mathrm{~m}$. Thickness of the skirt is $0.01 \mathrm{~m}$. The caisson is made of steel except the top lid which is made of transparent plexiglass. The tip of the caisson is a circular flat base. The detailed dimensions of the caisson are listed in Table 1. Six soil pressure sensors with a diameter of $0.02 \mathrm{~m}$ are embedded in the skirt wall of the caisson used for measuring the soil pressures acting on the skirt during installation. As shown in Fig. 3, three of them are toward inside and the remaining three are toward outside, and the sensors with the same subscripts are in the same heights from the skirt tip. The distances from the skirt tip to the soil pressure sensors are $0.06,0.18$, and $0.30 \mathrm{~m}$, respectively. Moreover, three micro soil pressure sensors with a diameter of $0.0095 \mathrm{~m}$ are embedded in the skirt tip equidistantly, to measure the tip resistance acting on the annulus. The micro soil pressure sensors are installed towards the underlying sand, and named T-1, T-2, and T-3 respectively. The instrumentation can provide a direct recognition on the tip resistance.

There are three valves on the top lid of the caisson, which are used for pumping, gas exit in the self-weight penetration stage, and suction transducer, respectively (see Fig. 4a). In the jacking installation tests, a hydraulic cylinder provides the reaction forces. The hydraulic cylinder is fixed on the steel reaction beam attached to the side walls of the platform (see Fig. 4b). The stable suction in the installation process is accomplished with an adjustable suction system, which consists of a vacuum pump, a vacuum regulating reservoir and several global valves. The vacuum regulating reservoir is set in the middle of the vacuum pump and the caisson through reinforced plastic pipes to provide a stable suction acting on the caisson, as shown in Fig. 4(c).

\subsection{Procedures}

Five tests were completed in this study: Ja-Inst-1, Ja-Inst-2, Su-Inst-3, Su-Inst-4 and Su-Inst-5, which could be classified into two kinds (see Table 2). The first two (Ja-Inst-1, Ja-Inst-2) are the jacking installation tests; Su-Inst-3, Su-Inst-4 and Su-Inst-5 are the suction installation tests. A summary of the test conditions and the corresponding hydraulic rates in the jacking installation tests is listed in Table 2. The purpose of the jacking installation tests is threefold. Firstly, it provides the unreduced penetration resistance under no pore water flow, which is relevant to the self-weight penetration. Secondly, the results of the resistance-displacement relation are compared with those of the 
suction installation tests to study the reduction effect, which is the base of the suction installation resistance calculation [12]. Thirdly, the jacking test results can offer a reference for the case of caisson installation in sand with clay layers, where the pore water flow can be prevented [11]. The purpose of Ja-Inst-2 is to study the effect of the penetration rates on the resistance.

Either kind of the tests is further composed of two different stages (the intermediate stage between the two for preparation is not included). For the jacking installation, in the first stage the caisson sinks into the sand bed till reaching the stable condition under self-weight. The valve for gas exit keeps open so the water and gas inside is released. The hydraulic jack is then added from the hydraulic cylinder and reaction beam. For the suction installation, the first stage is similar as the jacking installation; in the second stage, the gas exit valve is turned off and the adjustable suction system is then turned on to pump the gas and water out of the caisson. In Su-Inst-3, the suction was applied in five steps and the pressure is stable in each step with the values of $2.0 \mathrm{kPa}, 3.7 \mathrm{kPa}, 5.0 \mathrm{kPa}, 6.0 \mathrm{kPa}$ and $7.0 \mathrm{kPa}$, respectively.

As for Su-Inst-4 and Su-Inst-5, the aim is to investigate the effect of the loading process on the installation. Four steps of stable suction were applied in Su-Inst-4 with the values of $2.4 \mathrm{kPa}, 3.6 \mathrm{kPa}, 5.2 \mathrm{kPa}$ and $6.7 \mathrm{kPa}$ respectively. Three steps of stable suction were applied with the values of $3.0 \mathrm{kPa}, 4.8 \mathrm{kPa}$ and $6.5 \mathrm{kPa}$ respectively in Su-Inst-5. During each step, the suction was continued till the penetration of the caisson stopped sinking completely. The displacement of the caisson was tested with a pull rod displacement sensor and the tilt angle of the caisson was monitored with an inclinometer fixed on the caisson lid. The hydraulic force acting on the caisson was measured with a compression load cell mounted under the hydraulic cylinder. In the suction installation tests, an additional suction transducer was fixed on the top lid to record the suction within the skirt compartment of the caisson.

\section{Results of the jacking installation tests}

\subsection{Installation displacements and soil pressures}

The measured displacements of Ja-Inst-1 and Ja-Inst-2 tests are superimposed in Fig. 5. As we can see, the caisson penetrated about $11.4 \mathrm{~cm}$ into the sand bed under self-weight $(482 \mathrm{~kg})$ in Ja-Inst-1. The penetrating rate was simplified into uniform in the stage. Then the caisson was uniformly pushed down extra $38.2 \mathrm{~cm}$ with a rate of $0.1 \mathrm{~cm} / \mathrm{s}$ by the hydraulic cylinder in the second stage. The total penetration displacement was about $49.6 \mathrm{~cm}$ at last. With a different 
penetration rate, $0.2 \mathrm{~cm} / \mathrm{s}$, the results in Ja-Inst-2 test are used to examine the sensitivity of the penetration resistances to penetration rate. The final displacement of Ja-Inst-2 test was $48.3 \mathrm{~cm}$. In addition, the tilt angles in the above two tests were very small, varying in a range of $0.14-0.22^{\circ}$. The measured results show that the soil pressures and the penetration resistances are not sensitive to the rates within the range of $0.1-0.2 \mathrm{~cm} / \mathrm{s}$. Detailed analyses on the soil pressures are as follows and the contents about the penetration resistances are presented in section 3.2.

As shown in Fig. 3, the soil pressure sensors towards inside are denoted as I-1, I-2 and I-3, and the outside are O-1, O-2 and O-3. Fig. 6(a) and Fig. 6(b) show the curves of the soil pressures acting on the inside and outside of the skirt in Ja-Inst-1 test, respectively. As we can see, both the inner and outer soil pressures grow rapidly with the displacement. The inner soil pressures are almost equivalent to the outer. There is not a harder compaction in the inner sand under the current case $(z / D<0.34)$. The slope of the curves of the soil pressures varies in the range of $26.5 \sim 29.2 \mathrm{kPa} / \mathrm{m}$. As for the in situ condition, the lateral soil pressure can be calculated as

$$
p=K_{0} \gamma^{\prime} h+\gamma_{w} h_{w}=\left(K_{0} \gamma^{\prime}+\gamma_{w}\right) h+\gamma_{w}\left(h_{w}-h\right)
$$

where $\gamma^{\prime}$ is the submerged weight of the sand; $h$ is the depth of the soil pressure sensor below the sand surface; $\gamma^{\prime} h$ is the in-situ vertical effective soil pressure; $K_{0}$ is the lateral pressure coefficient, $K_{0} \approx 1-\sin \varphi^{\prime}=0.5[19] ; \gamma_{w}$ is the unit weight of water; $h_{w}$ is the depth of the soil pressure sensor below the surface of the water, $h_{w}=h+0.15 \mathrm{~m}$. So the slope of the in situ lateral soil pressure to depth is $\left(K_{0} \gamma^{\prime}+\gamma_{w}\right)=14.2 \mathrm{kPa} / \mathrm{m}$, much smaller than the range of $28 \sim 31 \mathrm{kPa} / \mathrm{m}$ of the test. This indicates that the sand around the skirt was strongly compacted during installation and the stress level of the sand was increased considerably due to soil-skirt interaction. Andersen et al. [11] recommended the lateral soil pressure coefficient $K$ within the range of $0.8-1.85$ for predicting the pressures on the skirt during installation through back-calculations of the test data of laboratory and field installation tests. When $K$ is chosen as 1.85 , the predicted slope is $26.12 \mathrm{kPa} / \mathrm{m}$ and close with the test results.

Fig. 7 shows the curves of the tip resistances measured by the sensors T-1, T-2 and T-3 in Ja-Inst- 1 test. As we can see, the unit tip resistance grew nearly linearly with the displacement, and it is much bigger than the inner and outer soil pressures on the skirt. Fig. 7 also shows the comparisons between the measured tip resistance and the predicted results with two different approaches, one is the API approach and the other is the $q_{c}$ method. API [20] calculates the tip resistance with the following equation 


$$
q_{\text {tip }}=p_{0} N_{q}
$$

where $p_{0}$ is effective overburden pressure at the skirt tip; $N_{q}$ is dimensionless bearing capacity factor. The relative density and measured cone resistance both indicate that the sand is medium dense. As for this sand type, API [20] suggests $N_{q}$ value of 40 . As for the $q_{c}$ method, the tip resistance is predicted as

$$
q_{\text {tip }}=k_{p} q_{c}(z)
$$

where $q_{c}(z)$ is the cone resistance at the depth $z$ under the sand surface; $k_{p}$ is the empirical coefficients, relating $q_{c}$ to the tip resistance. The cone resistance $q_{c}$ here is taken as the average value of the four CPT test results (see Fig. 2). In the UWA-05 method for driven piles, a $k_{p}$ value of 0.6 was suggested for the tip of open-ended piles, which may be appropriate for driven piles at deep depths (and thus high stress levels) [21]. As for the suction caisson in this research, the penetrating depth is much shallower and lower $k_{p}$ values are usually appropriate. In principle, this value should be adjusted according to the sand density, with higher values appropriate in looser sand, and even lower values possible for extremely dense sand. Senders and Randolph [12] suggested $k_{p}$ value of 0.2 for very dense sand. The silt sand is medium dense and a $k_{p}$ value of 0.35 is used for the prediction calculations. This $k_{p}$ value is very similar to the value of 0.3 given in $\mathrm{DnV}$ [22]. The prediction of the unit tip resistance with the $q_{c}$ method gives a very good agreement with the measurement, however, the prediction with API approach is much lower than the measurement (see Fig. 7).

\subsection{Predicted and test results of the unreduced installation resistance}

The penetration rate is constant in Stage II (see Fig. 5), so the installation resistance satisfies

$$
G^{\prime}+F=R=R_{f}+R_{t i p}
$$

where $G^{\prime}$ is the weight of the caisson, adjusted for buoyancy as increasing amounts of the caisson become submerged as the penetration proceeded; $F$ is the hydraulic force measured by the load cell placed between the hydraulic cylinder and the caisson; $R$ is the total installation resistance; $R_{f}$ is the skirt friction; $R_{t i p}$ is the tip resistance. According to weighing in advance and the measured $F$ curves, the curve of the installation resistance $R$ against the displacement is drawn, as shown in Fig. 8. The slope of the curves illustrates that the growth rate of the resistance increases gradually before the relative displacement $(z / D)$ reached 0.23 or so, and tended towards stability afterwards. The measured installation resistances are not sensitive to the penetration rates within $0.1-0.2 \mathrm{~cm} / \mathrm{s}$. 
The tip resistance is calculated based on the average values of the measured unit tip resistance and the tip area $\pi D t$. Then the skirt friction is determined as the net of the total resistance subtracting the tip resistance (see Fig. 9). The $q_{c}$ method is used here to make a prediction for the skirt friction, as

$$
R_{f}=\pi D_{I} \int_{0}^{z} k_{f} q_{c}(l) d z+\pi D_{o} \int_{0}^{z} k_{f} q_{c}(l) d z
$$

where $k_{f}$ is the empirical coefficients, relating $q_{c}$ to the skirt friction. An empirical value of $k_{f}=0.0018$ is able to give a good prediction of the skirt friction. The $k_{f}$ value of 0.0018 is higher than the most probable value of 0.001 recommended by DNV [22] and also slightly higher than the empirical values of 0.001 and 0.0015 used by Andersen et al. [11]. Additionally, in the UWA-05 method, Lehane et al. [21] recommended $k_{f}$ values for the lower two diameters of an open-ended pile, derived from installation data. The $k_{f}$ value was linked to the ratio of internal to external diameter $\left(D_{i} / D_{o}\right)$, as

$$
k_{f}=C\left[1-\left(\frac{D_{I}}{D_{O}}\right)^{2}\right]^{0.3} \cdot \tan \delta
$$

where the coefficient $C$ was suggested as $0.021 ; \delta$ is the interface friction angle. According to the measured soil pressures acting on the skirt and the skirt friction, $\delta$ is calculated using dynamic friction theory $(f=p \times \tan \delta)$, and the value of $\tan \delta$ is about 0.419 . For the present caisson with a $D_{i} / D_{o}$ ratio of 0.987 , the $k_{f}$ value is 0.003 , which is much higher for the present work. The $k_{f}$ value of 0.0018 here agrees well with the value used in Senders and Randolph [12]. Fig 8 shows the predicted total jacking installation resistance with $k_{f}=0.0018$ and $k_{p}=0.35$. It can be seen that the predicted results agree well with the experimental data.

\section{Results of the suction installation tests}

\subsection{Displacements and soil pressures}

Fig. 10 shows the applied suction (i.e. the absolute value of the negative pressure) beneath the top lid and the displacements of the caisson in the suction installation tests. In Su-Inst-3, the caisson sank into the sand bed $9.4 \mathrm{~cm}$ under self-weight and then penetrated $8.5 \mathrm{~cm}, 9.9 \mathrm{~cm}, 6.9 \mathrm{~cm}, 7.1 \mathrm{~cm}$ and $5.8 \mathrm{~cm}$ with the action of the corresponding step of stable suction (see Fig. 10a). In Su-Inst-4, the caisson firstly penetrated into the sand bed $11.6 \mathrm{~cm}$ in Stage I and then penetrated $7.6 \mathrm{~cm}, 7.8 \mathrm{~cm}, 9.1 \mathrm{~cm}$ and $8.4 \mathrm{~cm}$ with the action of the corresponding step of suction in Stage II (see Fig. 10b). As for Su-Inst-5, the displacements were $10.3 \mathrm{~cm}$ in Stage I, and $10.7 \mathrm{~cm}, 11.9 \mathrm{~cm}, 10.7 \mathrm{~cm}$ respectively in Stage II. 
It can be seen that when stable suction was applied, the displacement firstly grew linearly, and then the growth flattened out. Additionally, the tilt angles varied in the range of $0.2^{\circ}-0.4^{\circ}$ in the three suction installation tests. The tilt angles were much smaller, benefitting from the application of stable suctions, than those of our previous suction installation tests without suction adjustments, in which the tile angles usually exceeded $2^{\circ}$.

Fig. 11 shows the curves of the measured unit tip resistances against time in Su-Inst-3 test. It can be seen that the unit tip resistance proposes noticeable changes with the application of the suction. When a stable suction was applied, the suction caisson began to sink into the sand and the tip resistance slowly increased. The tip resistance tended towards stability after the penetration halted, while the suction still remained stable. At this point, the sum of the tip resistance and the skirt friction equals the sum of the suction load $\left(\pi D_{I}^{2} S / 4, S\right.$ is the applied suction) and the buoyant weight of the caisson. However, when the stable suction disappeared, the tip resistance dropped dramatically, because the suction load disappeared. Compared with the counterpart in jacking installation tests, the tip resistance in Su-Inst-3 is much smaller, due to seepage effect.

Fig. 12 shows the curves of the measured inner and outer soil pressures in Su-Inst-3 test. It can be seen that the soil pressures are very different from those of the jacking installation tests. The outer soil pressures increased when stable suction was applied. The inner soil pressures, however, decreased dramatically after stable suction was applied. Negative values occurred at the points where the penetration depth was small (see Fig. 12), due to the negative pressure within the caisson. The inner pressures were much lower than the outer when suction was applied. When the suction disappeared, the inner soil pressures grew suddenly and the outer pressures, however, barely changed. The values of the inner and outer pressures were nearly the same when suction disappeared. Compared with the counterparts in Ja-Inst-1, the inner soil pressures declined considerably when suction was applied, but the outer soil pressures were barely affected by the suction.

\subsection{Seepage effect on the installation resistance}

When the penetration halted at the end of each loading step, namely the equilibrium points, the total resistance $R$ were calculated as the sum of $G^{\prime}$ and suction load $\pi D_{I}^{2} S / 4$. Based on the measured data, the tip resistance and the inner and outer skirt frictions were also calculated at the equilibrium points. Fig. 13 shows the ratios the resistance of Su-Inst-3 test to the counterparts of Ja-Inst- 1 test. The ratios of the total resistance are $73.4 \%, 54.9 \%, 51.4 \%, 43.9 \%$ 
and $38.4 \%$, respectively. It can be seen that seepage effect is very apparent in the silt sand. The ratios of the inner friction at the five equilibrium points are $49.9 \%, 30.8 \%, 33.7 \%, 26.3 \%$ and $13.7 \%$, respectively. The ratios of the tip resistance are $73.4 \%, 53.6 \%, 49.6 \%, 41.3 \%$ and $34.8 \%$, respectively. The ratios of the outer friction are much bigger, with the values of $105.7 \%, 106.5 \%, 102.3 \%, 105.3 \%$ and $101.4 \%$, respectively. These ratios indicate that the suction is able to greatly reduce the inner friction and tip resistance, but the outer friction is barely influenced.

\subsection{Comparisons and discussions}

\subsubsection{Critical suction $S_{\text {crit }}$}

As mentioned before, suction is able to reduce the penetration resistance and beneficial to the installation in sand. However, when suction is applied, caution is needed to prevent piping. The critical state which may cause piping in the suction installation has been investigated using numerical methods by several researchers [12-14]. For example, Feld [14] proposed the critical suction $S_{\text {crit }}$ using the finite element program SEEP, as

$$
\frac{S_{c r i t}}{\gamma^{\prime} D}=1.32\left(\frac{z}{D}\right)^{0.75}
$$

Senders and Randolph [12] recommended the critical suction as

$$
\frac{S_{c r i t}}{\gamma^{\prime} D}=\left\{\pi-\arctan \left[5(z / D)^{0.85}\right]\left(2-\frac{2}{\pi}\right)\right\} \frac{z}{D}
$$

Moreover, the required suction $S_{\text {req }}$ for the installation in sand was approximately derived by Senders and Randolph [12], as

$$
S_{r e q}=\min \left(\frac{R_{f O}+R_{f I}+R_{t i p}-G^{\prime}}{R_{f I}+R_{t i p}+0.25 \pi D_{I}^{2} S_{c r i t}}, 1\right) S_{c r i t}
$$

According to the previous study, $S_{\text {req }}$ expressed in Eq. (9) should not exceed $S_{c r i t}$, in order to keep seepage stability of the inner sand. Otherwise, piping may occur. Fig. 14 shows the comparisons between the applied suctions in the tests and the calculated critical suction with Eq. (8). It can be seen that in the Su-Inst-3 test, the applied suctions are lower than the calculated critical suction. But in the Su-Inst-4 and Su-Inst-5 tests, there are some periods in which the aforementioned requirement is not fulfilled (see Fig. 14). Contrasting to the previous conclusions, no piping in the caisson was observed in the two tests. No sand boil was observed, the surface of the sand remained calm and the 
overlying water remained clear. The reason is due to the assumed critical state $i_{c r t i}=\gamma^{\prime} / \gamma_{w}$ (where $i_{c r t i}$ is the critical hydraulic gradient), based on which Eqs. (7) and (8) were established. In the critical state, the decreasing trend of the sand permeability with the increasing depth, which has proved to be able to increase the critical suction [23-24], was not taken into account. Additionally, the upward seepage flow made the inner sand looser and more permeable, which is also able to reduce the internal hydraulic gradient and raises the critical suction $[13,25]$. This implies that a potential exists for the suction to exceed the calculated $S_{c r i t}$ and the suction higher than the predicted with Eqs. (7) and (8) could be applied during suction installation.

\subsubsection{Resistance reduction ratio $\alpha$ and required suction $S_{\text {req }}$}

The resistance reduction ratio $\alpha$ is defined as

$$
\alpha=\left(R_{J}-R_{S}\right) / R_{J}
$$

where $R_{J}$ is the jacking penetration resistance; $R_{S}$ is the suction penetration resistance.

The resistance reduction ratios at the equilibrium points were calculated based on the test results of the two installation conditions. The reduction ratios of the inner friction and tip resistance were plotted in Figs. 15a and 15b respectively, against the ratios of the applied suction to $S_{\text {crit }}$ calculated with Eq. (8). As shown in Fig. 15, power functions fit the reduction ratios well by using the least square method. As for the inner friction, the reduction ratio $\alpha_{I}$ is expressed as

$$
\alpha_{I}=0.865 \times\left(S / S_{\text {crit }}\right)^{1.03}
$$

And the fitting formula for the tip resistance is as follow

$$
\alpha_{\text {tip }}=0.707 \times\left(S / S_{\text {crit }}\right)^{1.86}
$$

The $S_{\text {crit }}$ value in Eqs. (11) and (12) is calculated with Eq. (8), which does not account for a loosening effect and is therefore not the real critical value.

As for the outer friction, the values in the two test conditions are very close, with the reductions ratios within the range of $-0.02 \sim 0.07$. So the seepage effect on the outer friction can be ignored here, as

$$
\alpha_{o}=0
$$

The reduction ratio of the outer friction agrees well with that of Senders and Randolph [12]. However, the reduction ratios of the inner friction and tip resistance are different, as shown in Fig. 16. In the method of Senders and Randolph 
[12], the inner friction and tip resistance were both assumed to reduce linearly with $S / S_{\text {crit }}$ : remaining unchanged when $S=0$ and turning to zero when $S=S_{\text {crit }}$. The present reduction ratios of the inner friction and tip resistance are smaller and the ratio of the tip resistance shows strong nonlinearity.

Then based on Eqs. (11), (12) and (13), a new expression for $S_{\text {req }}$ is established, as

$$
S_{r e q}=\left[\left(1-\alpha_{t i p}\right) R_{t i p}+\left(1-\alpha_{I}\right) R_{f I}+\left(1-\alpha_{O}\right) R_{f O}-G^{\prime}\right] /\left(0.25 \pi D_{I}^{2}\right)
$$

In order to verify the new method, the required suctions in the suction tests were predicted with Eqs. (9) and (14) respectively. As shown in Fig. 17, the predicted results with Eq. (9) are lower than the measured, but the predicted results with Eq. (14) are in reasonable agreement with the observations. The predicted results with Eq. (14) are more exact and reliable for the installation of suction caissons in silt sand.

\section{Conclusions}

Suction caisson foundations have very good prospects in wind power projects along the offshore of eastern China. In the present study, several laboratory tests were carried out to investigate the installation of suction caissons in saturated silt sand. The thickness of the sand bed is $2.0 \mathrm{~m}$. The caisson used in the tests is made of steel with $1.5 \mathrm{~m}$ in the diameter and $0.5 \mathrm{~m}$ in the skirt length. Six pressure sensors are embedded in the skirt to record the soil pressures acting on the skirt wall. And three micro soil pressure sensors are embedded in the skirt tip to measure the tip resistance acting on the annulus. An adjustable suction system was designed to make stable vacuum in the caisson. Two comparative kinds of tests were completed based on with and without suction, namely jacking installation and suction installation.

For the jacking installation, the test results indicate that the inner and outer soil pressures acting on the skirt are close. The predictive performances of $q_{c}$ method and API approach are examined for jacking installation resistance. It shows that the jacking installation resistance can be better predicted with the cone resistance $q_{c}$ measured in the CPT tests, with the coefficients $k_{f}=0.0018$ and $k_{p}=0.35$. This paper examines It is demonstrated that the $q_{c}$ method provides better predictions. The tip resistance plays a main role in the jacking installation resistance. For the suction installation, the inner soil pressures and tip resistance drop when suction is applied. However, the outer soil pressures increase. Moreover, the measured data show that the inner skirt friction and tip resistance were reduced greatly due to seepage effect while the outer skirt friction nearly remained unchanged, compared with the counterparts in the jacking 
installation tests. Then using the measurements, the reduction ratios of the resistance were calculated. Power functions can be used to describe both the reduction ratios of the inner friction and tip resistance against $S / S_{\text {crit }}$. Based on the test results, a new prediction method for the required suction $S_{\text {req }}$ was established for the installation of suction caissons in slit sand, which proved more exact and reliable.

\section{Acknowledgements}

The authors would like to acknowledge the financial supports from National High Technology Research and Development Program of China (863 Program) (research grant 2012AA051702), International Science and Technology Cooperation Program of China (ISTCP) (research grant 2012DFA70490) and National Science Foundation for Innovative Research Groups (research grant 51021004).

\section{References}

[1] Zhu B, Kong D, Chen R, Kong L, Chen Y. Installation and lateral loading tests of suction caissons in silt. Canadian Geotechnical Journal 2011; 48: 1070-84.

[2] Jostad HP, Andersen KH. Potential benefits of using skirted foundations for jack-up platforms. In: Proc. of offshore technology conference. Houston. Paper No. OTC 18016. 2006.

[3] Ibsen LB. Implementation of a new foundations concept for offshore wind farms. In: Proc. of nordisk geoteknikermøte nr. 15. Norway. 2008. p. 19-33.

[4] Leblanc C. Design of offshore wind turbine support structures. Ph.D. Dissertation, Aalborg University at Aalborg; 2009.

[5] Barari A, Ibsen LB. Undrained response of bucket foundations to moment loading. Applied Ocean Research 2012; 36: $12-21$.

[6] Gao Y, Qiu Y, Li B, Li D, Sha C, Zheng X. Experimental studies on the anti-uplift behavior of the suction caissons in sand. Applied Ocean Research 2013; 43: 37-45.

[7] Houlsby GT, Ibsen LB, Byrne BW. Suction caissons for wind turbines. In: Proc. of int. symposium on Frontiers in Offshore Geotechnics. Perth, Western Australia. 2005. p. 75-94. 
[8] Villalobos FA, Byrne BW, Houlsby GT. Model testing of suction caissons in clay subjected to vertical loading. Applied Ocean Research 2010; 32: 414-24.

[9] Lian J, Ding H, Zhang P, Yu R. Design of large-scale pre-stressing bucket foundation for offshore wind turbines. Transactions of Tianjin University 2012; 18(2): 79-84.

[10] Achmus M, Akdag CT, Thieken K. Load-bearing behavior of suction bucket foundations in sand. Applied Ocean Research 2013; 43: 157-65.

[11] Andersen KH, Jostad HP, Dyvik R. Penetration resistance of offshore skirted foundations and anchors in dense sand. Journal of Geotechnical and Geoenvironmental Engineering 2008; 134(1): 106-16.

[12] Senders M, Randolph MF. CPT-based method for the installation of suction caissons in sand. Journal of Geotechnical and Geoenvironmental Engineering 2009; 135(1): 14-25.

[13] Erbrich CT, Tjelta TI. Installation of bucket foundations and suction caissons in sand - geotechnical performance. In: Proc. of offshore technology conference. Paper No. OTC 10990. Houston. 1999.

[14] Feld T. Suction buckets, a new innovative foundation concept, applied to offshore wind turbines. Ph.D. Dissertation, Aalborg University at Aalborg; 2001.

[15] Houlsby GT, Byrne BW. Design procedures for installation of suction caissons in sand. Geotechnical Engineering 2005; 158(3): 135-44.

[16] Ibsen LB, Thilsted CL. Numerical study of piping limits for suction installation of offshore skirted foundations and anchors in layered sand. In: Proc. of int. symposium on frontiers in offshore geotechnics. Perth, Western Australia. 2011. p. 421-26.

[17] Guo Z, Wang L, Yuan F, Li L. Model tests on installation techniques of suction caissons in a soft clay seabed. Applied Ocean Research 2012; 34: 116-25.

[18] Lian J, Chen F, Wang H. Laboratory tests on soil-skirt interaction and penetration resistance of suction caissons during installation in sand. Ocean Engineering 2014; in press.

[19] Jaky J. The coefficient of earth pressure at rest. Journal of the Society of Hungarian Architects and Engineerings 1944; 7: 355-58.

[20] American Petroleum Institute (API). Recommended practice for planning, designing and constructing fixed offshore platforms - working stress design API Recommended Practice 2A-WSD (RP2A-WSD), 21st Ed. 2000. 
[21] Lehane BA, Schneider JA, Xu X. The UWA-05 method for prediction of axial capacity of driven piles in sand. In: Proc of int. symposium on frontiers in offshore geotechnics. Perth, Western Australia. 2005. p. 19-21.

[22] Det Norske Veritas. Foundations. DNV Recommended Practice Classification notes No. 30.4, Hovik; 1992.

[23] Tran MN, Randolph MF, David WA. Study of seepage flow and sand plug loosening in installation of suction caissons in sand. In: Proc. of 15th int. offshore and polar engrg. conf. 2005. p. 516-21.

[24] Harireche O, Mehravar M, Mlani AM. Suction caisson installation in sand with isotropic permeability varying with depth. Applied Ocean Research 2013; 43: 256-63.

[25] Tran MN, Randolph MF. Variation of suction pressure during caisson installation in sand. Geotechnique 2008; 58(1): $1-11$. 


\section{List of captions}

Tables

Table 1 Details of the caisson dimensions

Table 2 Outline of the tests carried out 


\section{Figures}

Fig. 1. Grading curve for the sand bed.

Fig. 2. CPT results of the test sand: Cone resistance, $q_{c}(\mathrm{MPa})$.

Fig. 3. Sketch view of the test caisson: $D=1.5 \mathrm{~m}$.

Fig. 4. (a) Snapshot of the caisson; (b) snapshot of the testing platform; (c) suction installation apparatus.

Fig. 5. Curves of the displacements against time of Ja-Inst-1 and Ja-Inst-2 tests.

Fig. 6. Curves of soil pressures measured in Ja-Inst-1: (a) inner soil pressures; (b) outer soil pressures.

Fig. 7. Curves of the unit tip resistance measured in Ja-Inst-1 and comparisons with the predicted.

Fig. 8. Curves of the total resistances measured in Ja-Inst-1 and Ja-Inst-2 tests and comparisons with the predicted.

Fig. 9. Comparisons between the measured and predicted results of skirt friction in Ja-Inst-1 test.

Fig. 10. Loading schemes adopted in the suction installation tests: (a) Su-Inst-3; (b) Su-Inst-4; (c) Su-Inst-5.

Fig. 11. Variations of unit tip resistance in Su-Inst-3 test: (a) T-1; (b) T-2; (c) T-3.

Fig. 12. Variations of soil pressures acting on the skirt wall in Su-Inst-3: (a) I-3; (b) O-3; (c) I-2; (d) O-2; (e) I-1; (f) O-1.

Fig. 13. Ratios of the installation resistances of Su-Inst-3 to the counterparts of Ja-Inst-1.

Fig. 14. Comparisons between the applied suctions and calculated critical suction with Eq. (8): (a) Su-Inst-3; (b) Su-Inst-4; (c) Su-Inst-5.

Fig. 15. Reduction ratios of inner friction and tip resistance versus the ratios of the applied suction to the critical suction calculated with Eq. (8): (a) $\alpha_{I}$; (b) $\alpha_{\text {tip }}$.

Fig. 16. Comparisons between the present reduction coefficients and the previous.

Fig. 17. Comparisons between the applied suction and predicted required suction: (a) Su-Inst-3; (b) Su-Inst-4; (c) Su-Inst-5. 
Table 1 Details of the caisson dimensions

\begin{tabular}{ccccc}
\hline $\begin{array}{c}\text { Diameter } \\
D(\mathrm{~m})\end{array}$ & $\begin{array}{c}\text { Skirt } \\
\text { length } \\
L(\mathrm{~m})\end{array}$ & $\begin{array}{c}L / D \\
\text { ratio }\end{array}$ & $\begin{array}{c}\text { skirt } \\
\text { thickness } \\
(\mathrm{m})\end{array}$ & $\begin{array}{c}\text { Self-weight } \\
(\mathrm{kg})\end{array}$ \\
\hline 1.5 & 0.5 & 0.33 & 0.01 & 482 \\
\hline
\end{tabular}

Table 2 Outline of the laboratory tests carried out

\begin{tabular}{|c|c|c|c|c|c|}
\hline $\begin{array}{l}\text { Caisson } \\
\text { diameter } \\
(\mathrm{m})\end{array}$ & Case & Code & $\begin{array}{c}\text { Penetration } \\
\text { rate } \\
(\mathrm{cm} / \mathrm{s}) \\
\end{array}$ & Procedures & Note \\
\hline \multirow{5}{*}{1.5} & 1 & Ja-Inst-1 & 0.1 & \multirow{2}{*}{$\begin{array}{l}\text { Phase I self-weight penetration, } \\
\text { Phase II jacked penetration }\end{array}$} & \multirow{2}{*}{$\begin{array}{l}\text { Jacked by the } \\
\text { hydraulic cylinder }\end{array}$} \\
\hline & 1 & Ja-Inst-2 & 0.2 & & \\
\hline & 2 & Su-Inst-3 & - & \multirow{3}{*}{$\begin{array}{l}\text { Phase I self-weight penetration, } \\
\text { Phase II suction penetration }\end{array}$} & \multirow{3}{*}{$\begin{array}{l}\text { Pumping using the } \\
\text { regulation reservoir }\end{array}$} \\
\hline & 2 & Su-Inst-4 & - & & \\
\hline & 2 & Su-Inst-5 & - & & \\
\hline
\end{tabular}


Figure 2

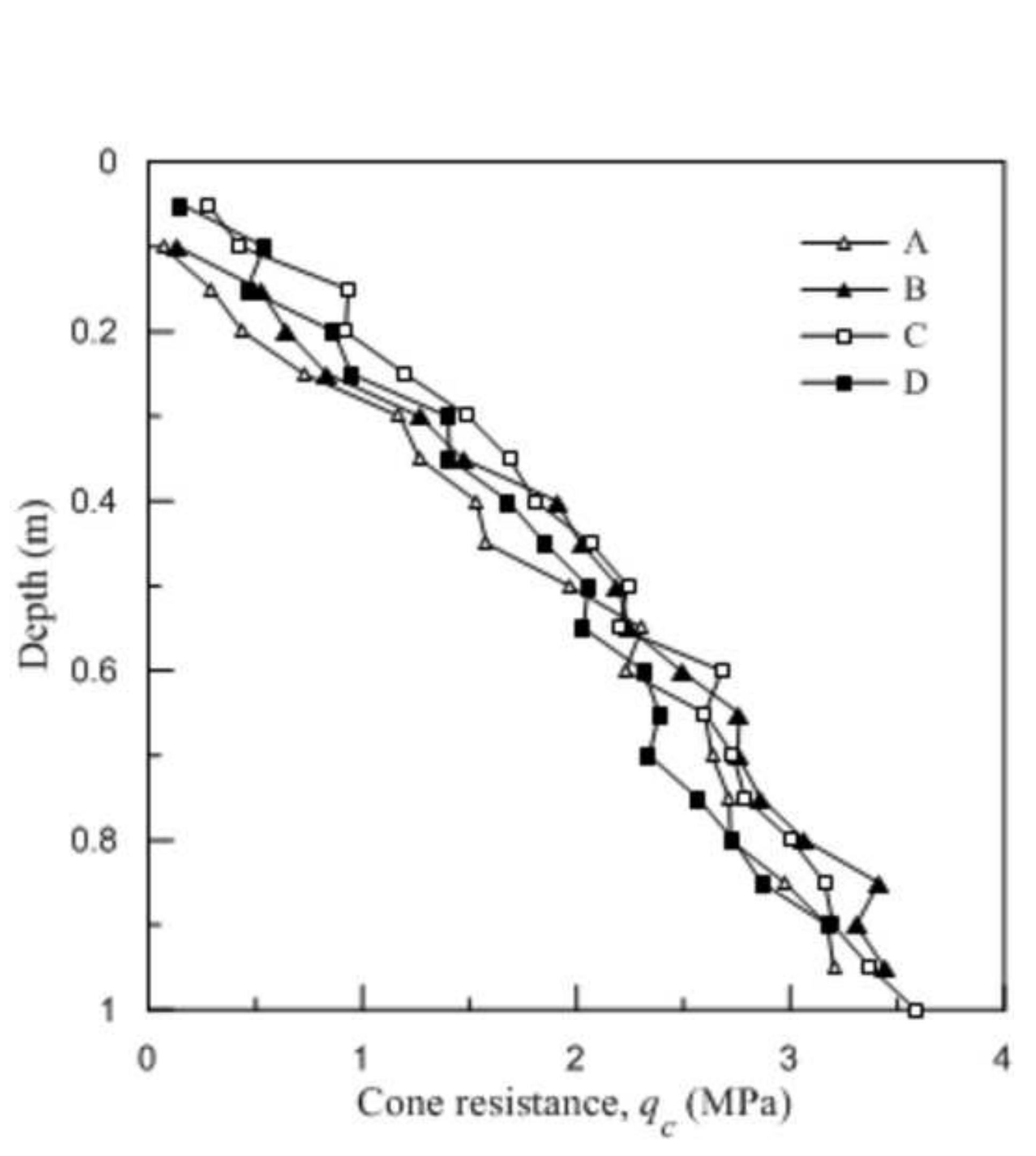

\section{2}




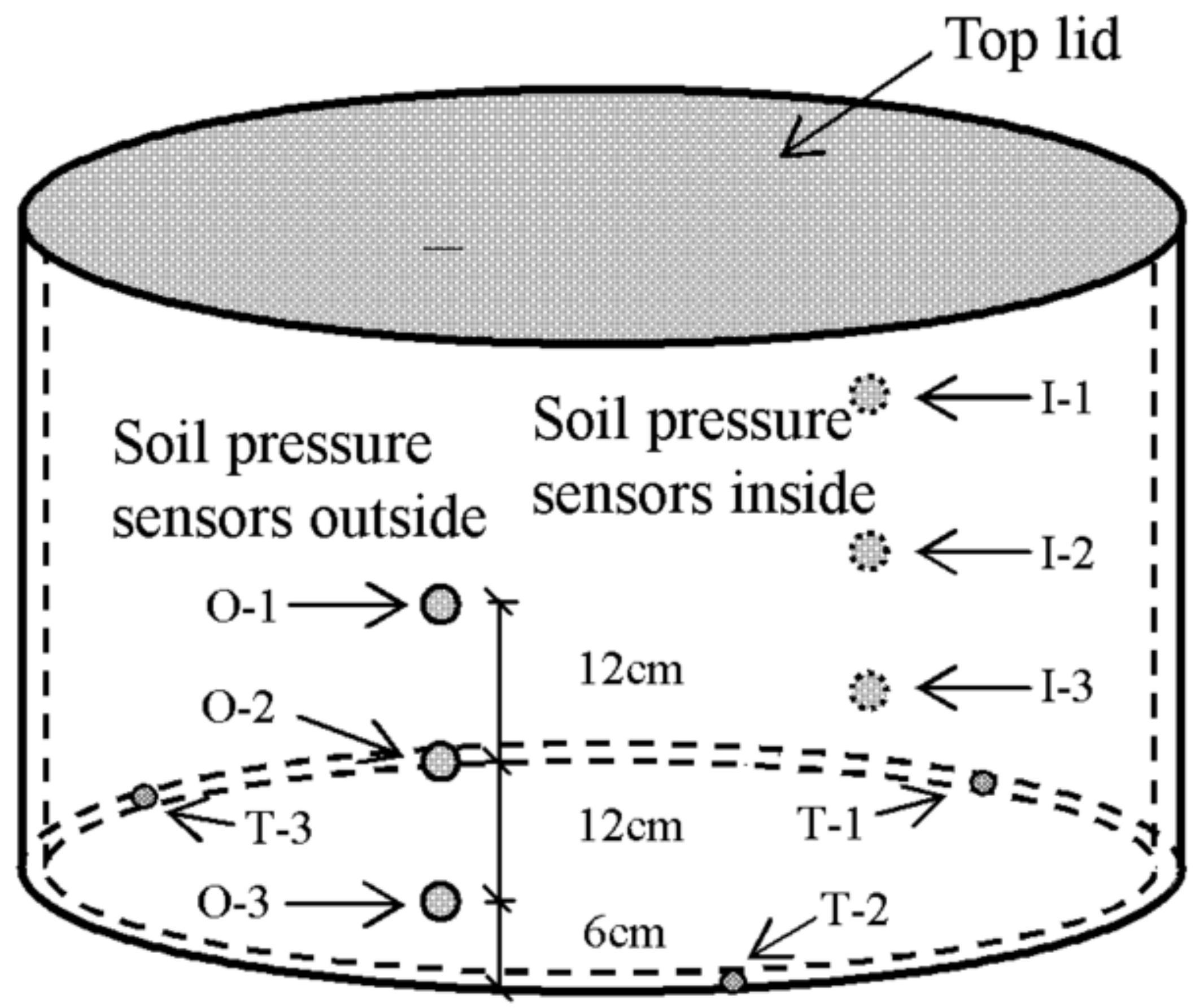


(a)
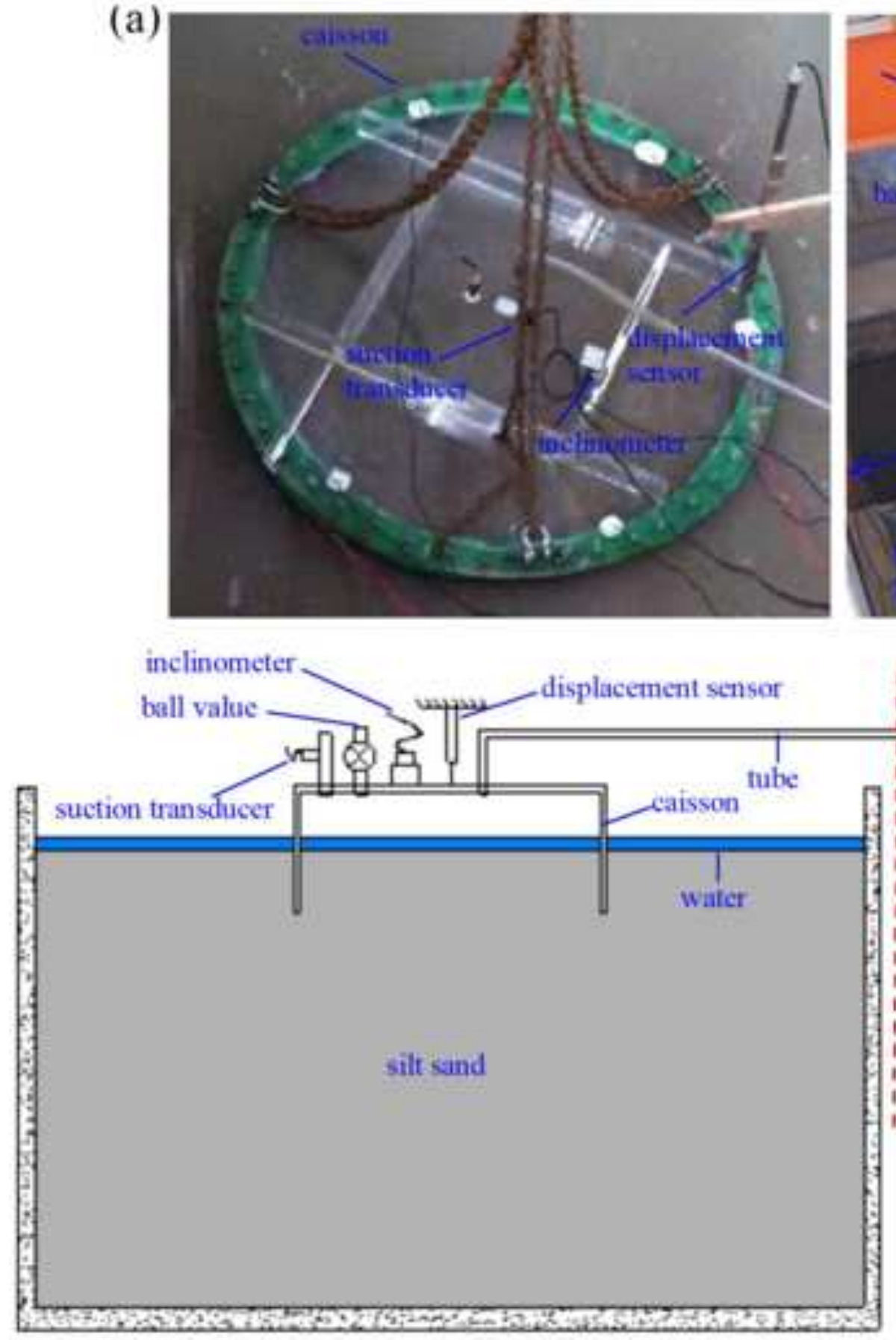

(c) (b)

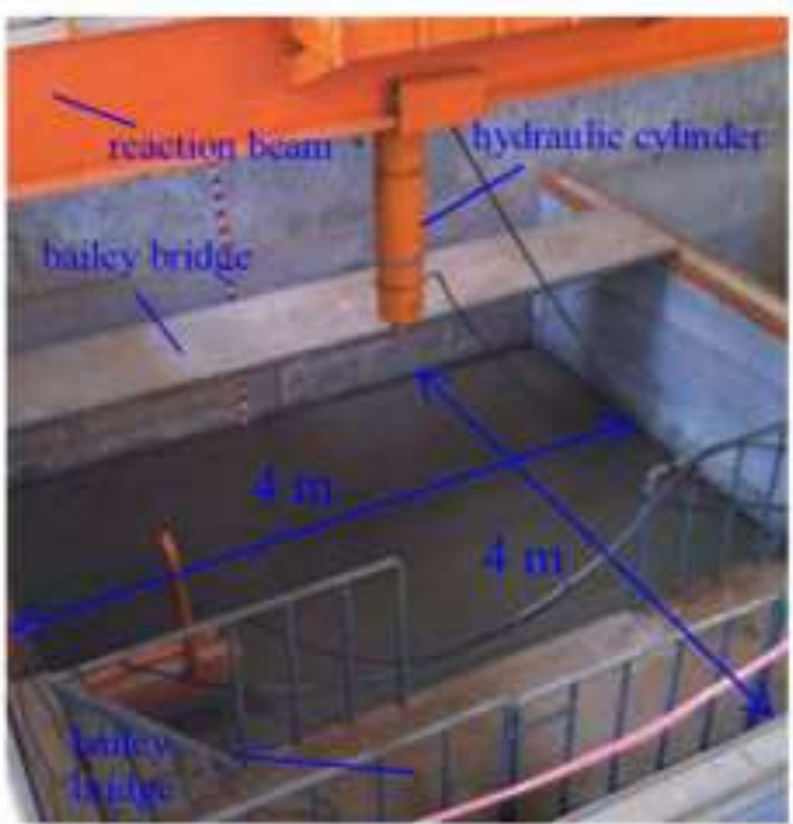

connecting the ;

tube vacuum pump
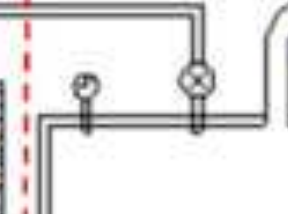

vacuum gauge
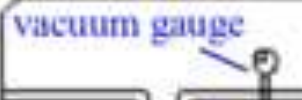

\&ball value :

vacuum regulating reservoir

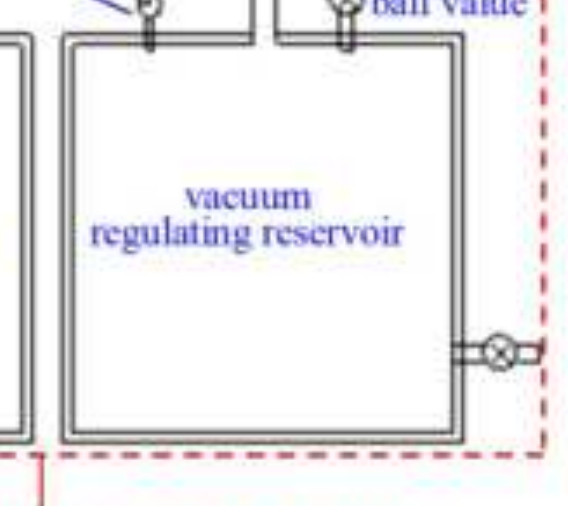

adjustable suction system 


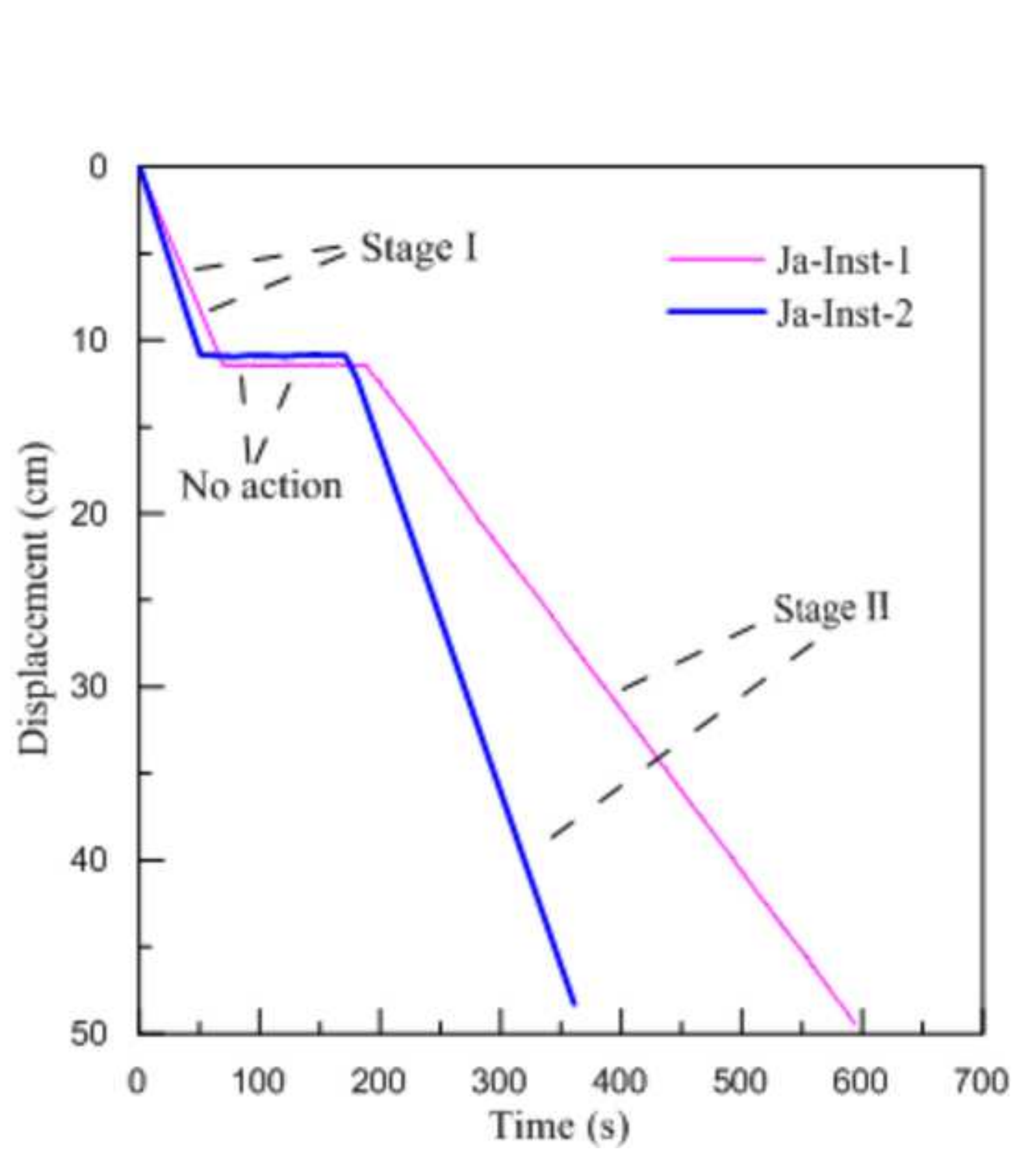

Figure 5

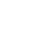

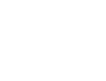

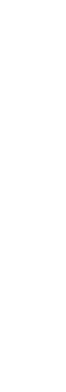

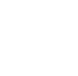



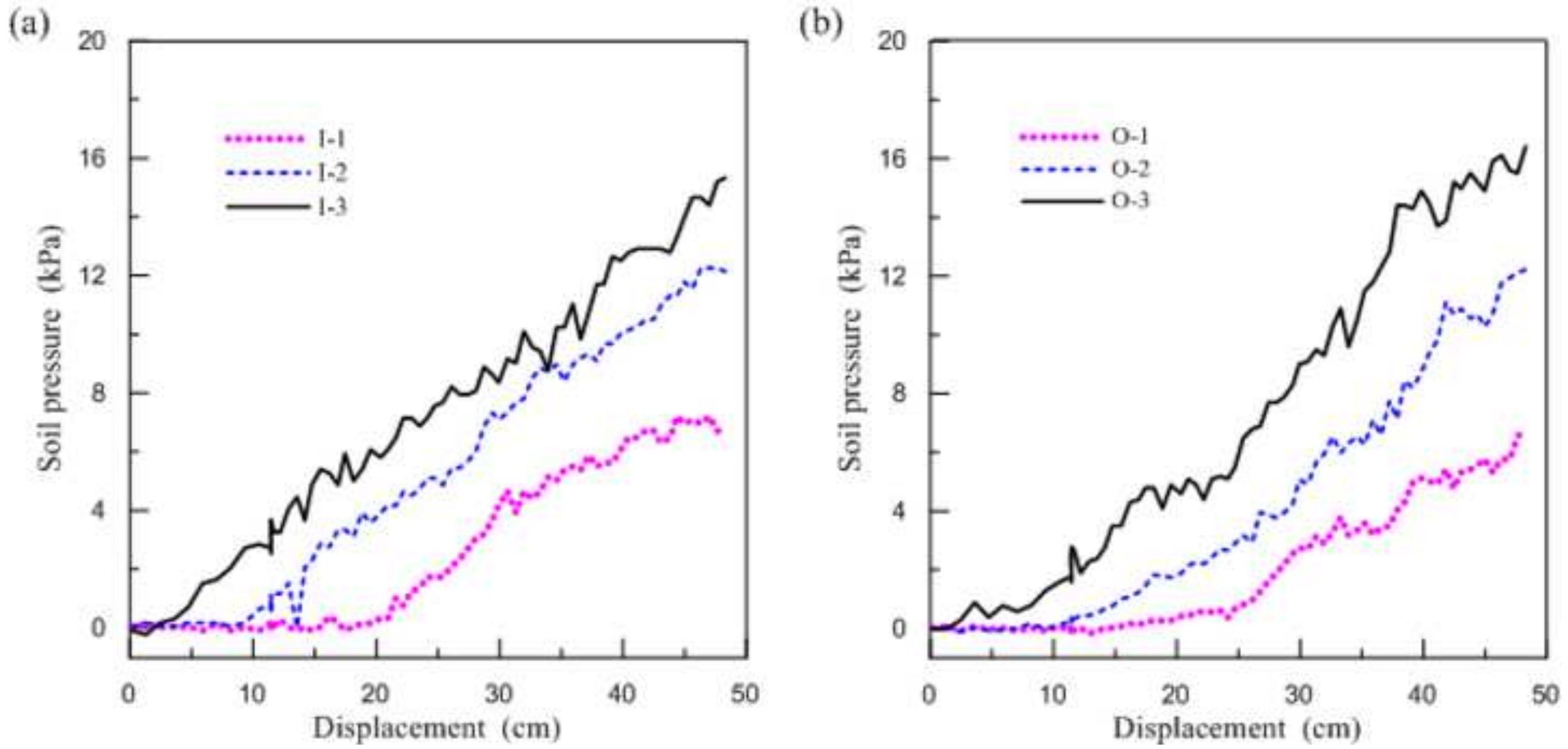


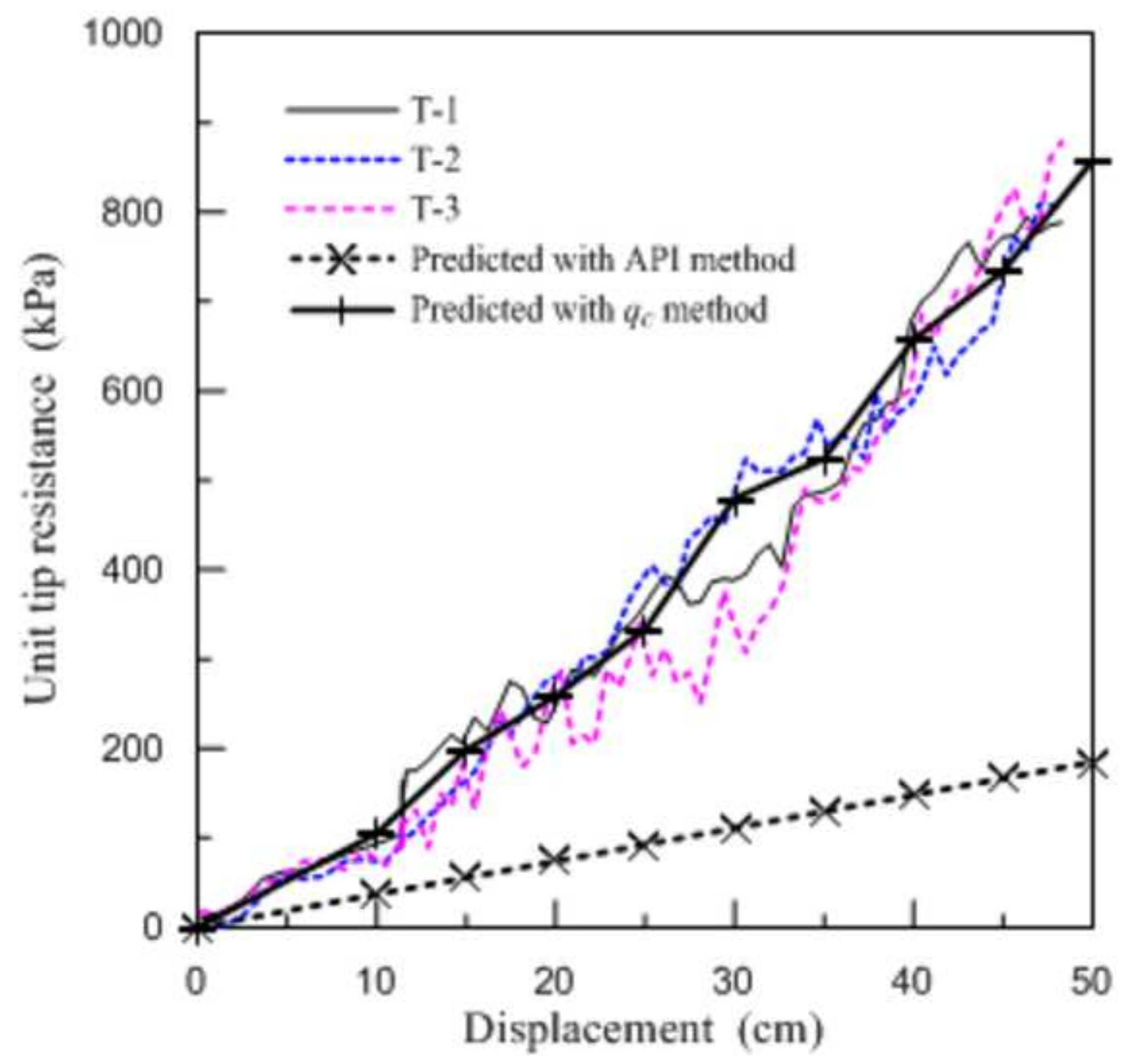




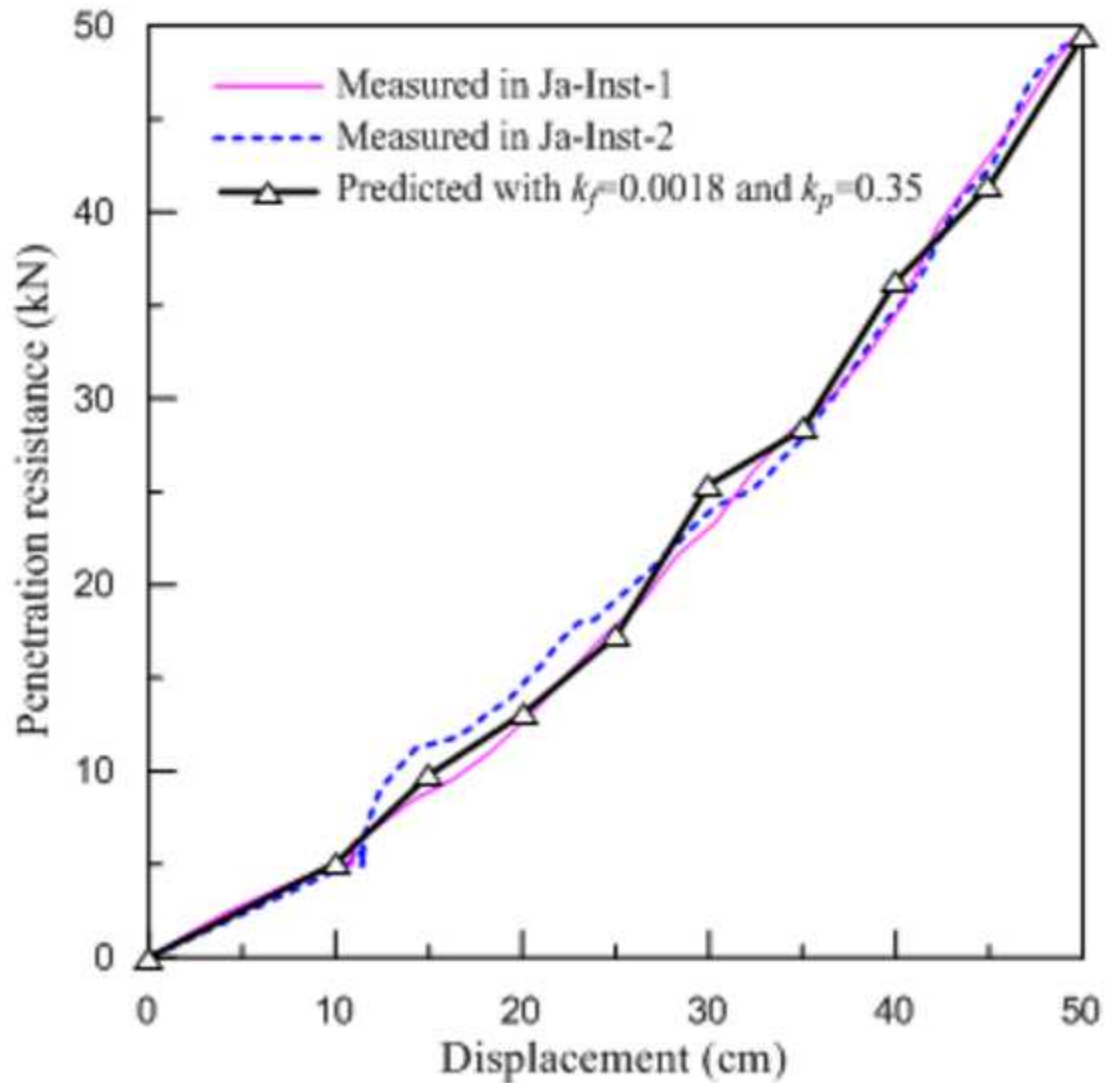




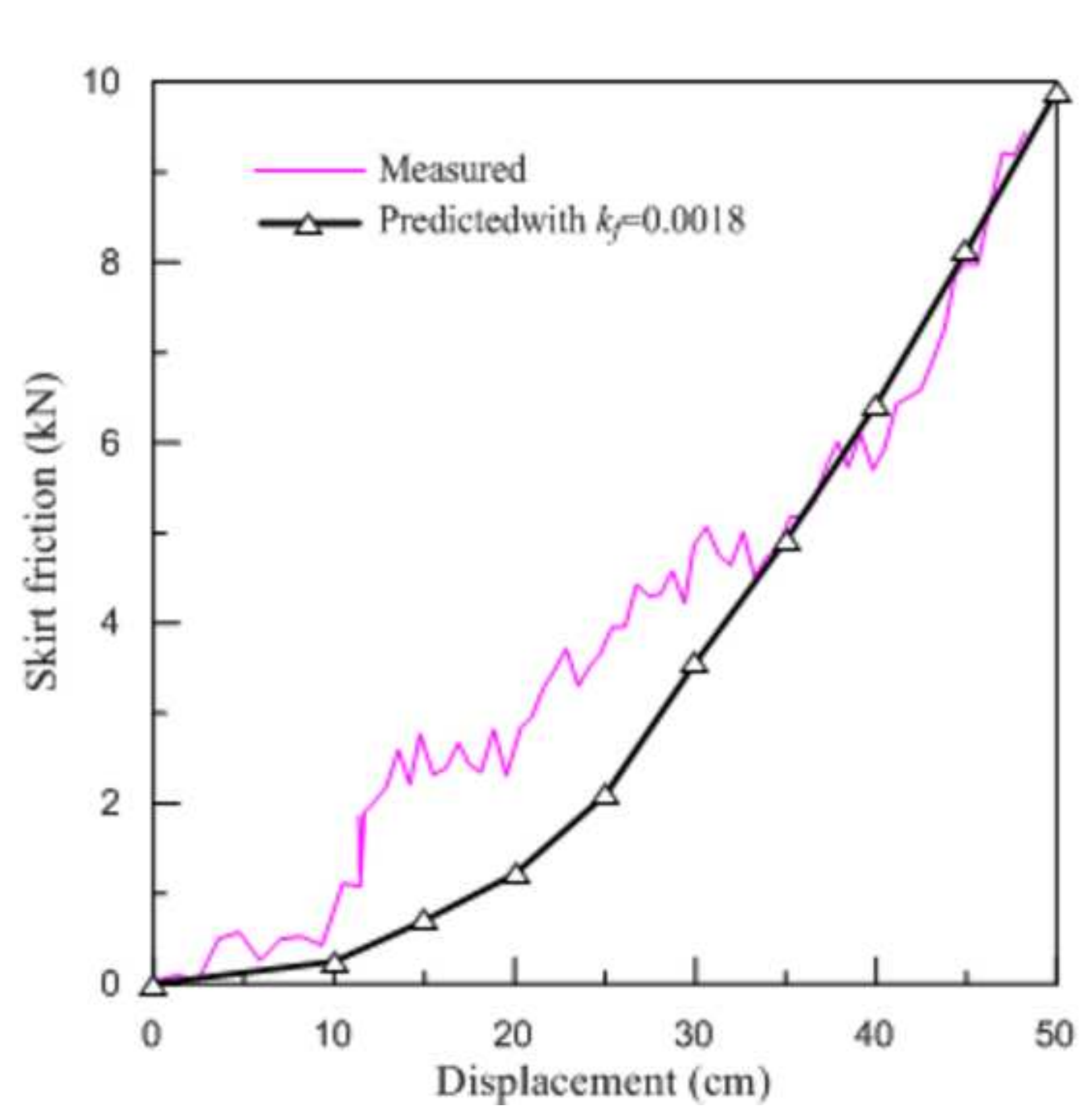

Figure 9 

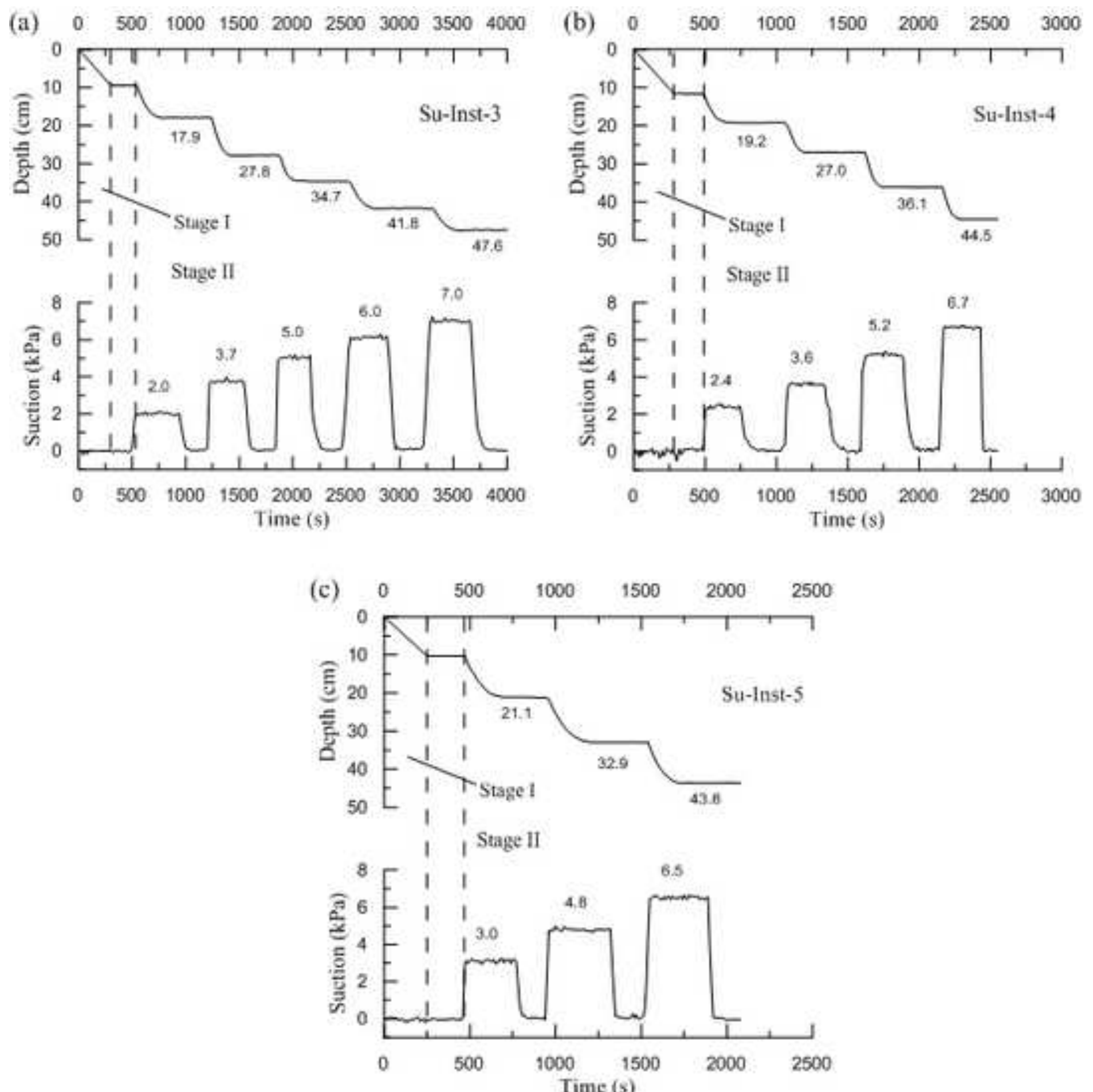

Time (s) 
Figure 11

(a)

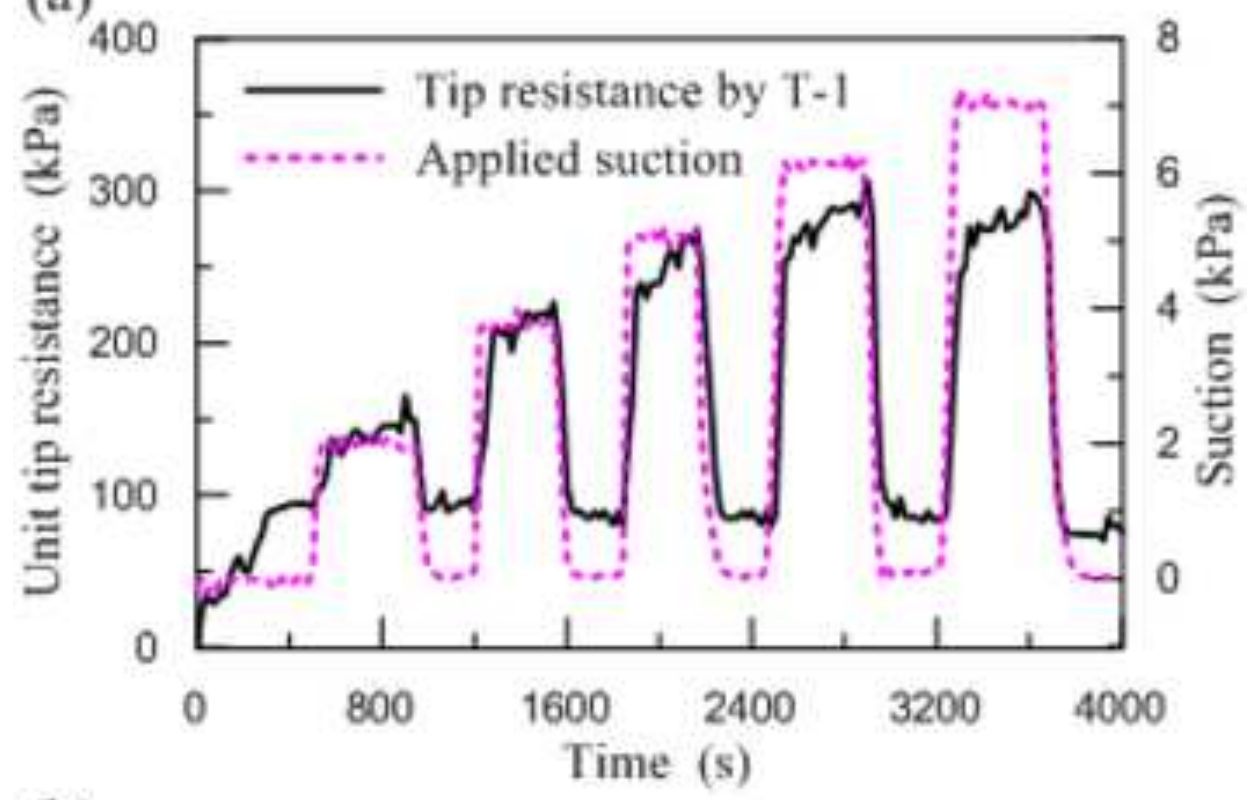

(b)

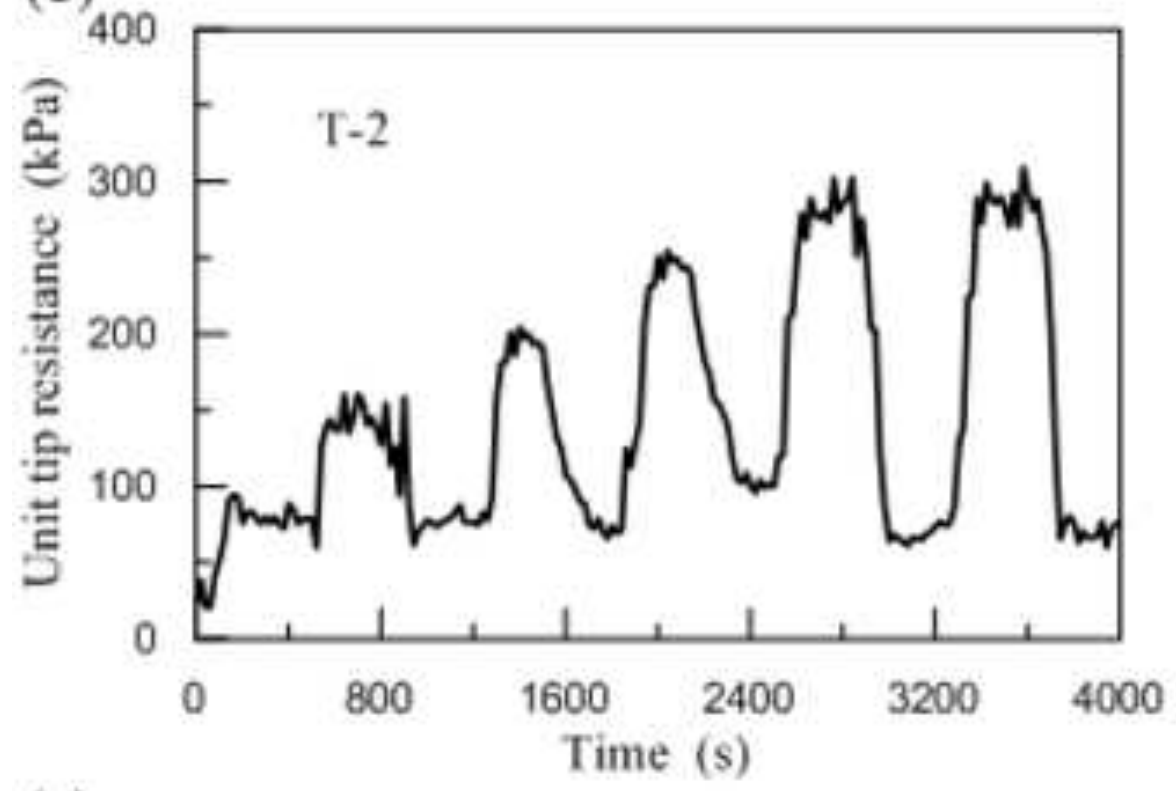

(c)

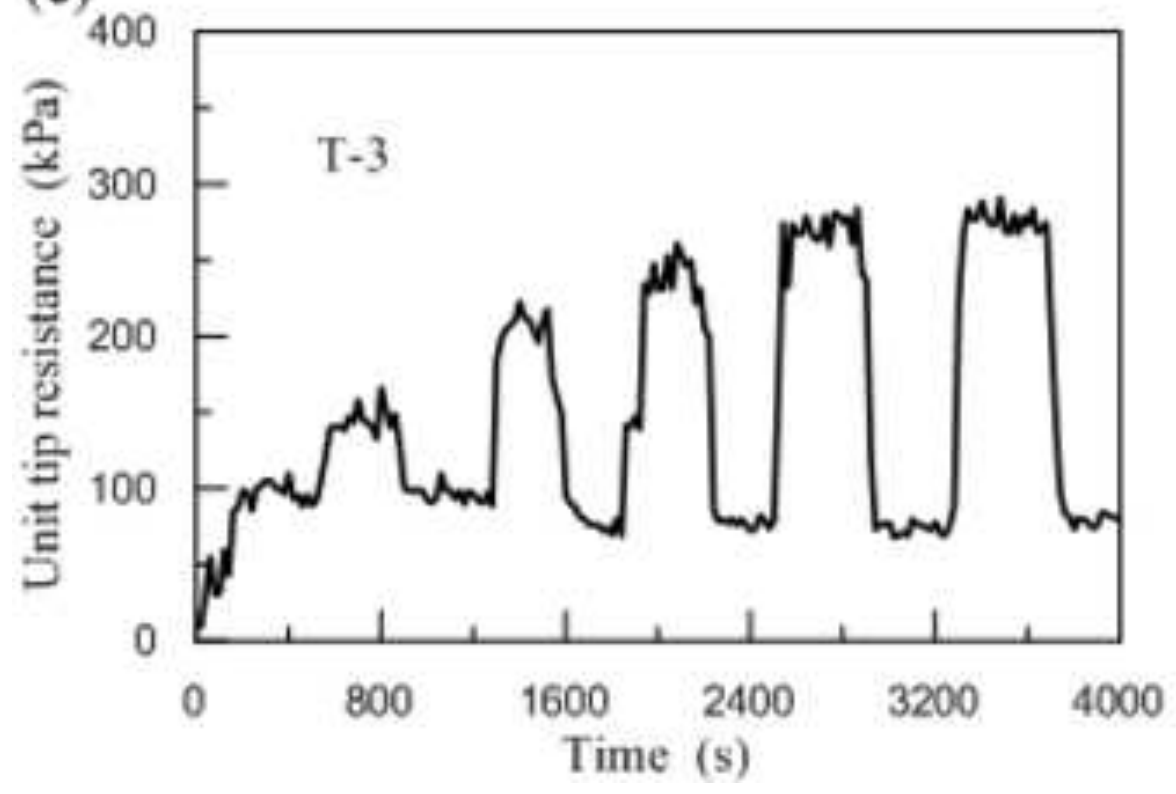


(a)

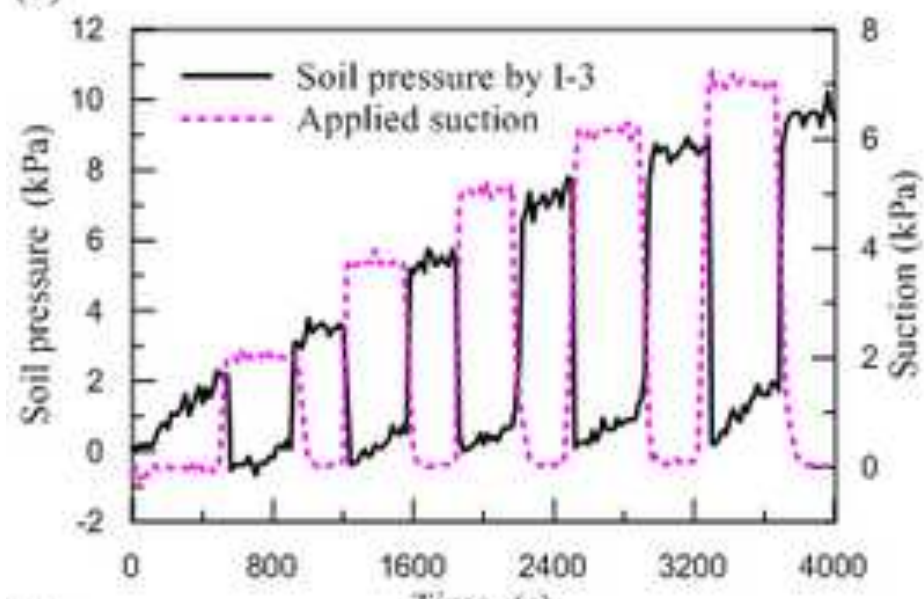

(c)

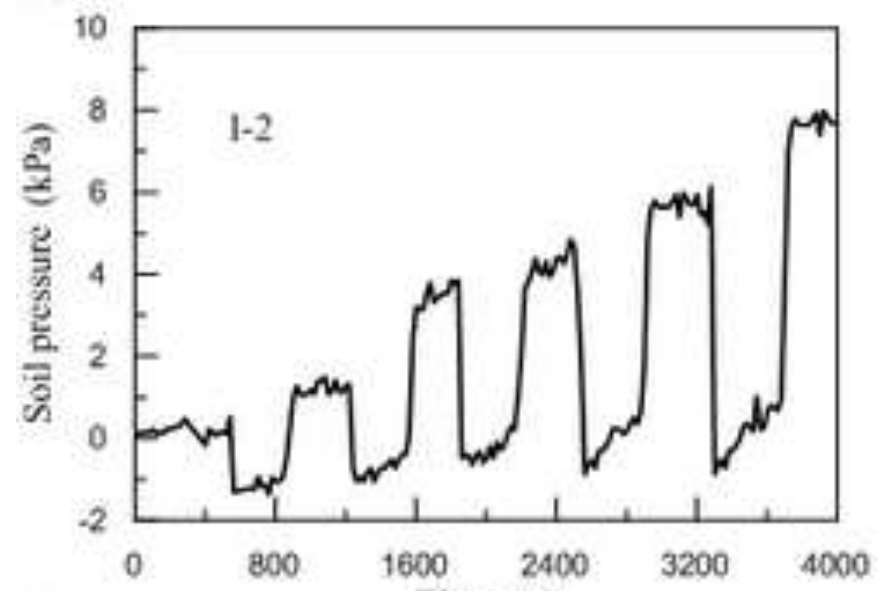

(e)

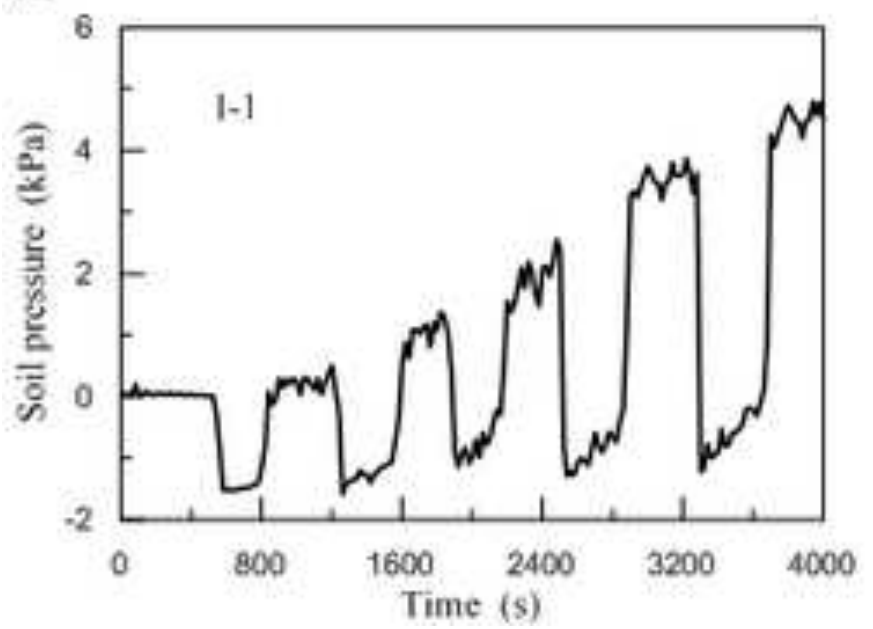

(b)

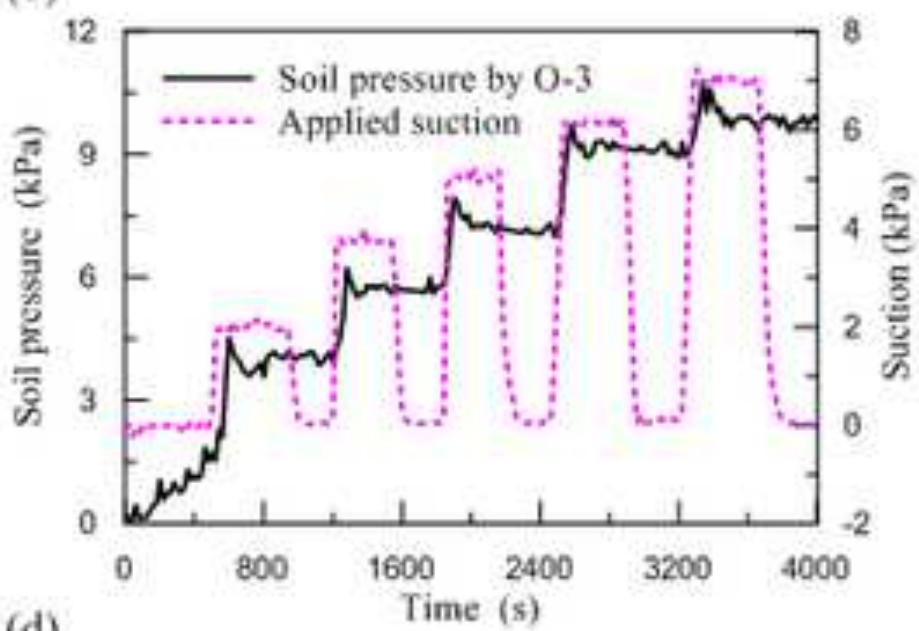

(d)

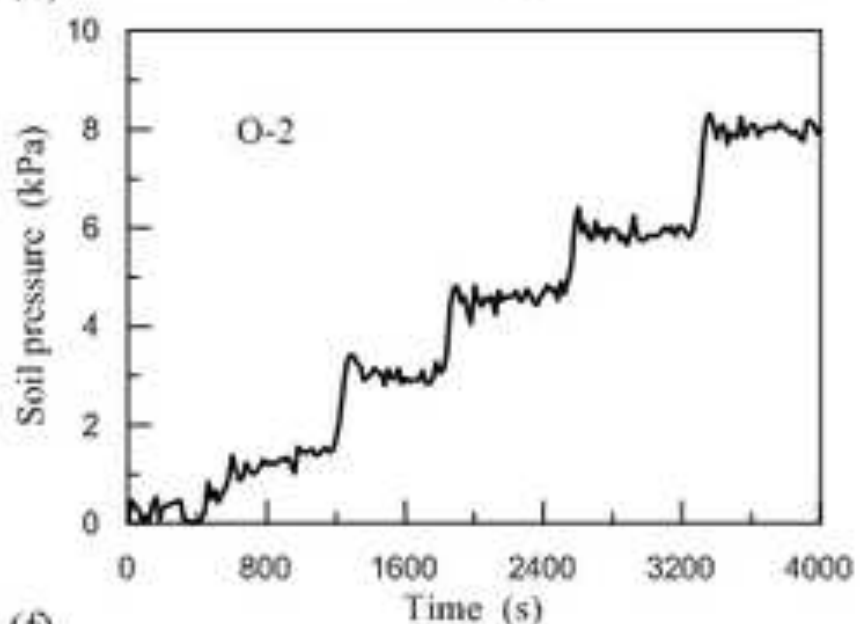

(f)

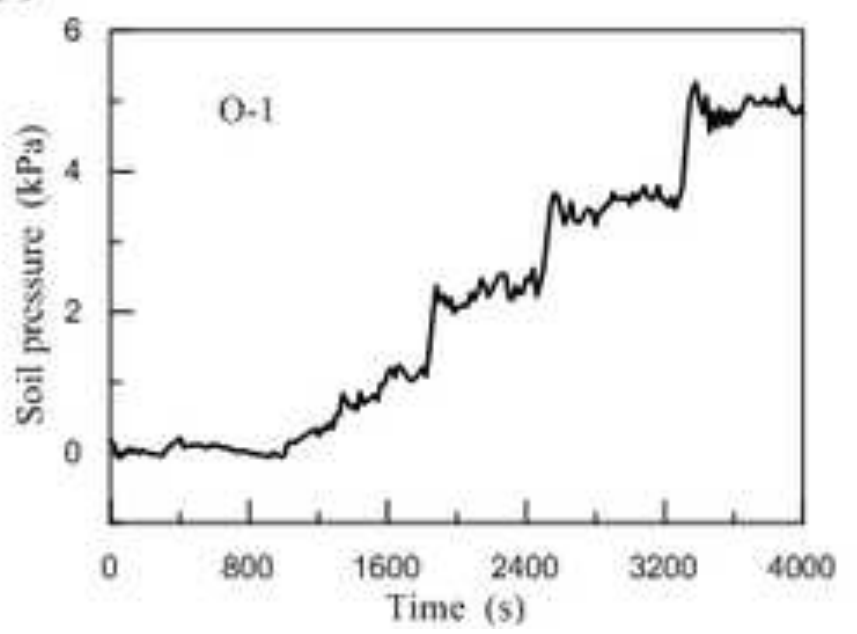




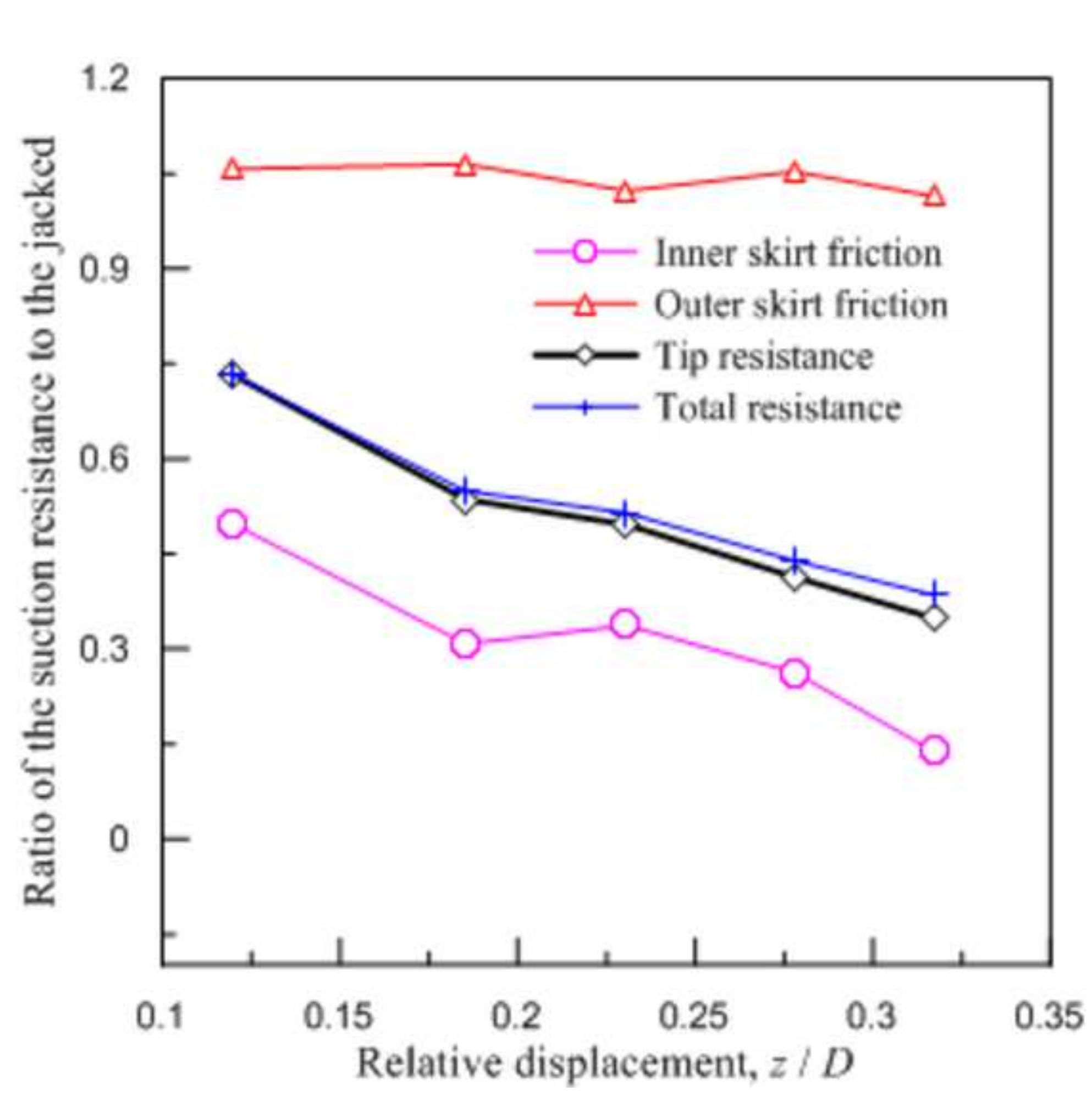



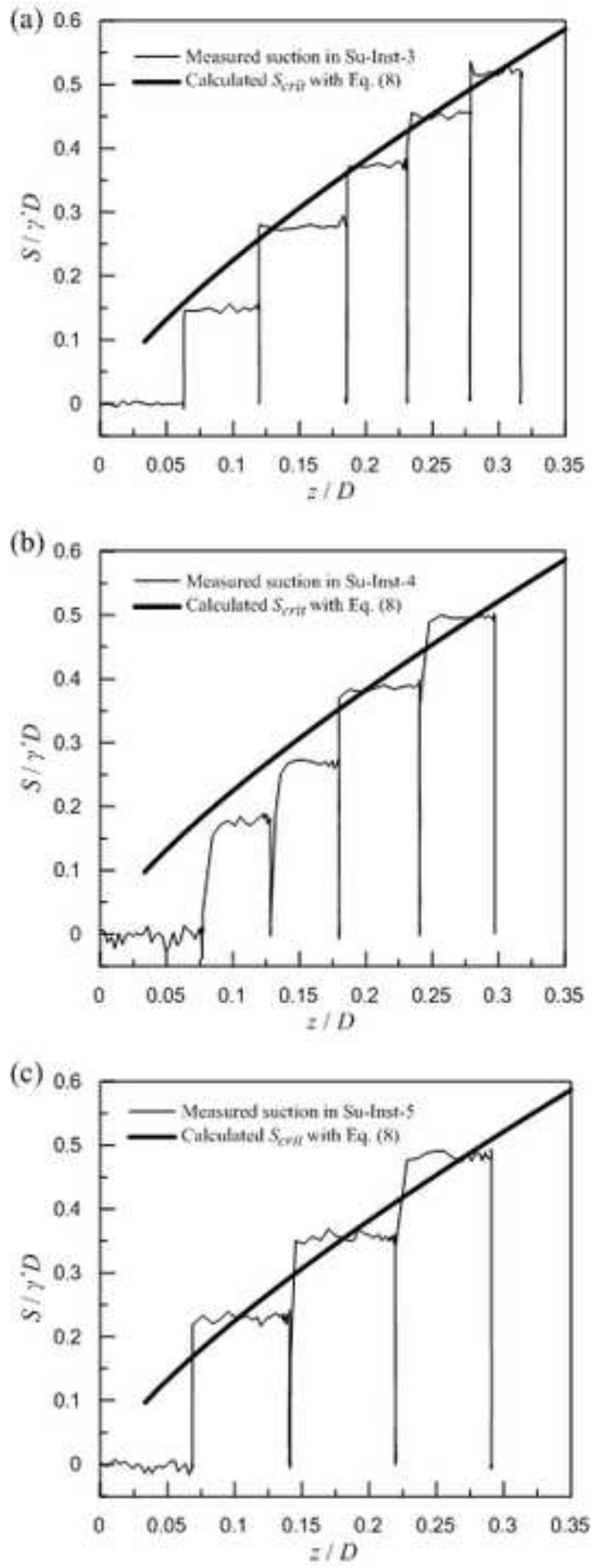

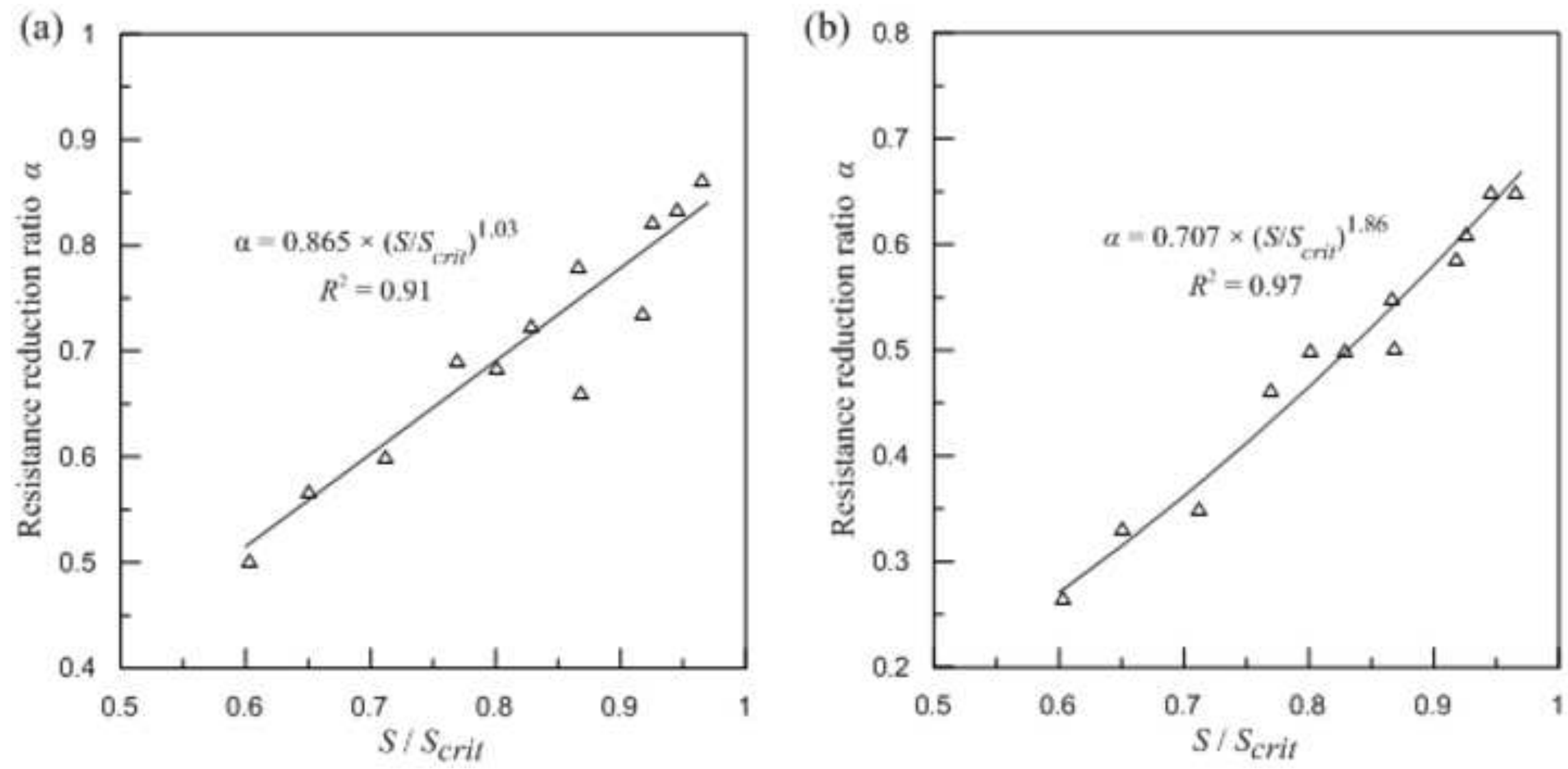


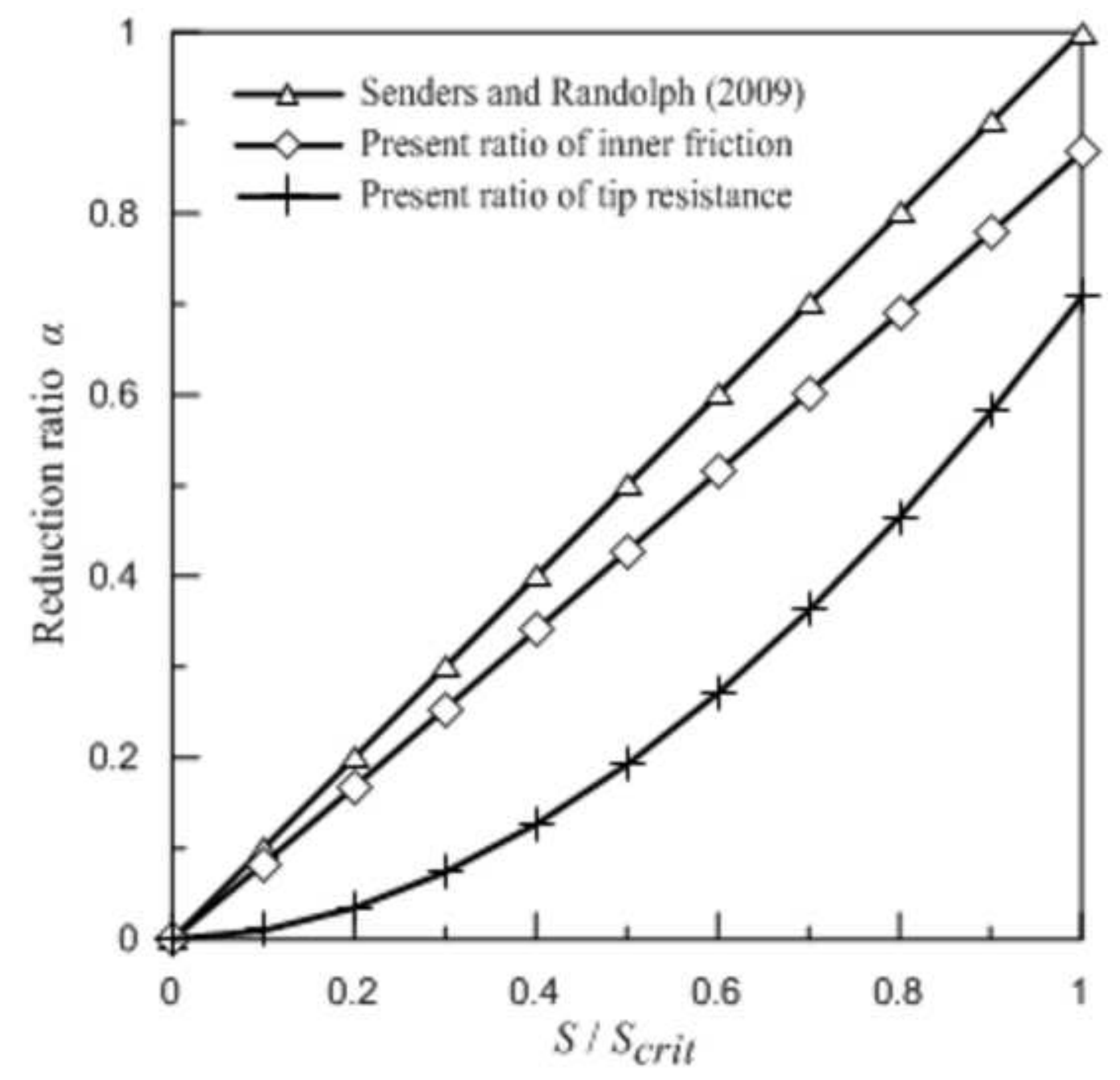



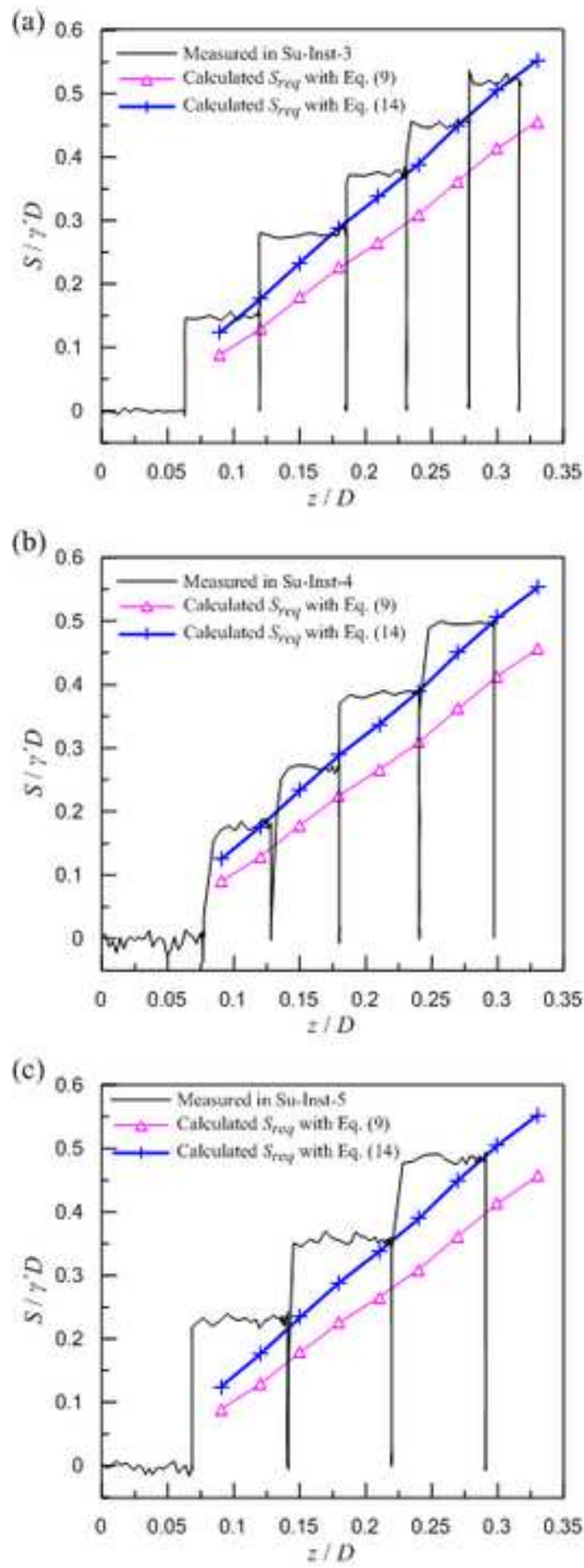